\title{
EL PAPEL DE LOS DEFENSORES DEL PUEBLO COMO IMPULSORES DE LA MODIFICACIÓN DEL ORDENAMIENTO JURÍDICO: UNA GARANTÍA ADICIONAL DE DESARROLLO DEL ESTADO SOCIAL
}

\author{
MANUEL GARCÍA ÁLVAREZ \\ Catedrático de Derecho de Constitucional \\ Universidad de León \\ Ex Procurador del Común de Castilla y León \\ RUBÉN GARCÍA LÓPEZ \\ Asesor Coordinador del Procurador \\ del Común de Castilla y León
}
SUMARIO
I. Introducción: una declaración de inten- ciones.
II. Estado social y procesos de innovación normativa.
III. Intervención de los defensores del pue- blo en los procesos de cambio normati- vo.
IV. La participación en la modificación del ordenamiento jurídico: una nueva di- mensión de la actuación de los defenso- res.
V. Consideraciones finales: los defensores ante una evolución normativa necesaria en el Estado social.

\section{INTRODUCCIÓN: UNA DECLARACIÓN DE INTENCIONES}

No parece discutible afirmar que las normas jurídicas constituyen la materia prima esencial con la cual los defensores del pueblo desarrollan su labor de defensa de los derechos de los ciudadanos, a través de la supervisión de la 
actuación de las administraciones públicas. Ahora bien, no es unívoca la relación que puede, o debe, ser mantenida por estas instituciones con las normas que reconocen, desarrollan y tratan de trasladar a la realidad los derechos y principios a cuya protección se consagran aquellas. En efecto, no cabe únicamente una postura estática limitada a verificar si la norma de que se trate es aplicada de forma correcta y eficaz por el sujeto público, sino que también es posible, conveniente y deseable una actitud dinámica, que contemple también el cambio en la norma como medio idóneo para el desarrollo de la importante misión encomendada a los defensores, con consecuencias tanto para los casos particulares que se les planteen como, con carácter general, para toda la ciudadanía.

Es objeto del presente trabajo confrontar estas dos realidades (defensores del pueblo y ordenamiento jurídico), una institucional y otra normativa, analizar las relaciones que se establecen entre ambas en un Estado como el constitucionalizado en la actualidad en España, y explorar las oportunidades que ofrece una actitud activa de los primeros frente a posibles modificaciones del segundo. Aunque esta perspectiva relativa a la actuación de los defensores puede ser calificada de ambiciosa, su análisis no hace necesario despegarse de la regulación actual de estas figuras, y, por tanto, no debe ser ajena a las previsiones contempladas en la actualidad en sus normas reguladoras.

Pero antes de continuar es necesario delimitar los conceptos sobre los que vamos a tratar porque, aunque pueda parecer innecesario definir a estos efectos realidades tan generales como las que aquí nos van ocupar, se hace imprescindible determinar, cuando menos, de forma negativa aquellas, con el fin de manifestar claramente a quién o a qué no nos vamos a referir en las siguientes líneas.

Así, en primer lugar, desde una perspectiva internacional, en la obra clásica en este ámbito $E l$ Ombudsman ${ }^{1}$, Donald C. Rowat, partiendo de la institución original sueca, señalaba que esta figura debe poseer los siguientes rasgos:

«El Ombudsman es un funcionario independiente y no influido por los partidos políticos, representante de la legislatura, por lo general establecido en la Constitución, que vigila a la Administración; se ocupa de quejas específicas del público contra las injusticias y errores administrativos; y tiene el poder de investigar, criticar y dar publicidad a las acciones administrativas pero no el de revocarlas" ${ }^{2}$.

1 ROWAT, D.C, The Ombudsman: Citizen's Defender, London, George Allen and Unwin Ltd., 1968, pág.39. Otra obra clásica en el análisis de las características generales de estas instituciones es la escrita por GELLHORN, W. Ombudsmen and Others: Citizen's Protectors in Nine Countries, Cambridge (Massachussets), Harvard University Press, 1966.

2 En un sentido similar, el Ombudsman clásico es definido por el Instituto Internacional del Ombudsman de la siguiente forma: "The office of a person who has been appointed or elected pursuant to an Act of the Legislature; whose role is to investigate citizen complaints concernig administrative acts or decisions of government agencies from which the Ombudsman is independent; and who makes recommendations to the Legislature as an officer of that body". 
Descendiendo al ámbito nacional, y siguiendo con carácter general las definiciones indicadas, vamos a limitar nuestro análisis a los defensores de base parlamentaria en los que, debido a su elección por un órgano legislativo, las notas de legitimidad democrática e independencia del poder ejecutivo se encuentran en un primerísimo plano. No es superfluo, ni muchísimo menos, hacer descansar en la elección parlamentaria el carácter definitorio de los defensores del pueblo ante la proliferación, quizás desmesurada, de defensores sectoriales y locales en numerosos ámbitos, en sus diversas denominaciones de defensores de los ciudadanos o de los usuarios de múltiples sectores. Al respecto, ya en el año 1999, fecha desde la cual la aparición de este tipo de figuras no ha hecho más que incrementarse, los defensores del pueblo trataron esta cuestión y aprobaron un documento denominado Reflexiones de los comisionados parlamentarios en torno a la creación de defensores sectoriales y locales, donde los que eran entonces titulares de estas instituciones manifestaron expresamente que

"esta proliferación de Ombudsman a la que venimos asistiendo en los más variados ámbitos, a la vez que pone de manifiesto la eficacia de este modelo institucional, no deja de arrojar alguna sombra de duda sobre tal fenómeno, ya que la indiscriminada multiplicidad de instituciones con similar denominación puede terminar diluyendo el propio concepto de Ombudsman, que, de difuminarse, pudiera ver afectada su finalidad de garantizar los derechos y libertades, $n^{3}$.

Por tanto, la exigencia de la elección por el órgano legislativo limita nuestro estudio a la Institución del Defensor del Pueblo, prevista en el artículo 54 de la Constitución Española, y a los comisionados autonómicos generales creados hasta la fecha cuya elección corresponde a los órganos legislativos de cada Comunidad ${ }^{4}$.

3 En el mismo documento, adoptado en Madrid el 18 de noviembre de 1999, se concluía también lo siguiente: «la Constitución, los distintos Estatutos de Autonomía y sus leyes reguladoras crean la figura del defensor del pueblo, en sus diversas denominaciones como una institución de garantía que viene a completar el sistema de protección de derechos y libertades reconocido a los ciudadanos; definen estas instituciones con unos perfiles muy precisos en cuanto a su naturaleza jurídica, configuración institucional y funciones, en ausencia de los cuales no puede hablarse de auténticos defensores del pueblo; configuran a los defensores del pueblo como instituciones de carácter unipersonal a las que atribuyen la defensa de todos los derechos del conjunto de los ciudadanos". Por tanto, "este marco constitucional, estatutario y legal preexistente condiciona el desarrollo y creación de otras figuras similares, cualquiera que fuera su ámbito, y deberá ser respetado, en todo caso, para no afectar al fin último y primordial que deben perseguir todas estas figuras de defensa de los derechos e intereses de los ciudadanos".

4 Como indica M. CARRILLO, «En todos los casos son elegidos por el órgano parlamentario mediante mayorías cualificadas que hacen preciso siempre un amplio acuerdo entre los partidos con representación parlamentaria, a fin de conseguir el mayor consenso posible para el titular o titulares de la Institución" ("Los defensores en el Estado español de acuerdo con la Constitución y los Estatutos de Autonomía", Ponencia publicada en Estados compuestos y Ombudsdman: experiencias europeas, Barcelona, Universidad Autónoma de Barcelona, marzo de 2007. págs. 78 y 79. 
En cuanto a la denominación genérica de defensores del pueblo que vamos a utilizar, la misma viene impuesta por los diferentes nombres que han sido utilizadas en varias Comunidades Autónomas para designar a estas instituciones. En este sentido, la presencia del dato historicista en la configuración del hecho autonómico en la Constitución se ha visto trasladado a la nomenclatura empleada, en el nivel estatutario y legislativo, para identificar a varios comisionados parlamentarios autonómicos 5 .

Además de la necesidad de generalizar, la utilización de la expresión defensores del pueblo para referirnos a la realidad institucional estudiada no nos desagrada, estando muy lejos de aquellos que han criticado con dureza la denominación terminológica utilizada en el artículo 54 de la Constitución ${ }^{6}$. Por el contrario, no han faltado quienes han elogiado la muestra de buen criterio y de autocontrol lingüístico manifestada por algunos parlamentos autonómicos, como el andaluz, al escoger la denominación de Defensor del Pueblo, evitando de esta forma riesgos de confusión a la ciudadanía con el empleo de términos distintos para designar instituciones de función análoga, aunque ejercida en ámbitos territoriales diferentes?

Configurados los defensores del pueblo, de forma general, como aquellos comisionados elegidos por órganos legislativos para la defensa de los derechos de los ciudadanos frente a la actuación de las administraciones públicas, procede ahora establecer los límites, a los efectos del presente trabajo, de lo que debemos entender por ordenamiento jurídico. Evidentemente, esta delimitación únicamente puede ser enormemente genérica y su única finalidad es enmarcar adecuadamente las reflexiones que se realizarán a continuación.

Para un estudio exhaustivo del concepto de ordenamiento jurídico, y más en concreto de ordenamiento jurídico-administrativo, podemos remitirnos a cualquiera de las obras generales de derecho administrativo que analizan con profusión su definición y configuración ${ }^{8}$. Lo que nos interesa destacar aquí es la identificación de las fuentes integrantes del aquel ordenamiento en relación

5 EMBRID IRUJO, A. El control de la Administración pública por los comisionados parlamentarios autonómicos, Madrid, Ministerio para las Administraciones Públicas, octubre de 1991, págs. 37 y 38

6 Esta denominación ha sido calificada de excesivamente grandilocuente que puede dar lugar a ilusiones indebidas" (PELLÓN RIVERO, R., El Defensor del Pueblo, Madrid, Servicio Centro de Publicaciones de la Presidencia del Gobierno, 3. ${ }^{\text {a }}$ ed., 1984, pág. 44); o incluso como "cuasi insultante (...) como si esa o esas personas no debieran ser Pueblo y no las únicas elegidas para defender al pueblo (...) los demás no somos defensores del pueblo; hay uno o varios individuos a quienes se da una especie de carrera administrativa (si no es política) de Defensores del Pueblo" (FAIRÉN GUILlÉN, V., El Defensor del Pueblo. Ombudsman, vol. I, Parte General, Madrid, Centro de Estudios Constitucionales, 1982, pág. 15).

7 PÉREZ LUÑO, A., Nuevos retos del Estdo Constitucional: Valores, derechos, garantías. Cuadernos Democracia y Derechos Humanos núm. 2. Servicio de Publicaciones, Cátedra de Democracia y Derechos Humanos. Universidad de Alcalá / Defensor del Pueblo, 2010, pág. 130.

8 Por todas ellas, GARCÍA DE ENTERRÍA, E. y FERNÁNDEZ T., Curso de Derecho Administrativo, Madrid, Civitas, Undécima edición, 2002, págs. 67-90. 
con el contenido de las cuales pueden los defensores del pueblo intervenir de una forma relevante. Estas fuentes serán fundamentalmente dos: Ley y Reglamento.

En cuanto a la Ley, respecto a lo que aquí nos interesa, consideraremos comprendida dentro de este concepto cualquier norma jurídica de rango legal, con independencia del poder del Estado, ejecutivo o legislativo, que la apruebe. Por tanto, se incluyen aquí las leyes aprobadas por las Cortes Generales y por las asambleas legislativas de las Comunidades Autónomas, así como los decretos-leyes y los reales decretos-legislativos adoptados por el Gobierno o por el órgano ejecutivo de una comunidad autónoma.

La segunda de las fuentes antes indicadas es el Reglamento, entendiendo por tal, de una forma simplificada, a toda norma escrita dictada por la Administración, sea esta estatal, autonómica o local. Sin perjuicio de lo que más adelante se afirmará, es, precisamente, a través del ejercicio de la potestad reglamentaria como las administraciones públicas intervienen de forma más directa e intensa, al menos cuantitativamente, en la formación y desarrollo del ordenamiento jurídico aplicable en un territorio.

En definitiva, sin olvidar las notas de organización y estructura que configuran de una forma esencial a todo ordenamiento jurídico, de acuerdo con los objetivos del presente trabajo aquí nos tomaremos la licencia de tomar por tal a la fuente principal que lo nutre, que no es otra que la ley en el sentido material del término (norma jurídica), que es el utilizado, por ejemplo, en el artículo 6 del Código Civil.

Defensores del pueblo y ordenamiento jurídico, así configurados, son elementos de carácter institucional y normativo que deben combinarse adecuadamente para que los primeros cumplan la función que tienen atribuida y para que las normas jurídicas que integran el segundo respondan adecuadamente al desarrollo y a una garantía de efectividad de los derechos y principios constitucional y estatutariamente recogidos. No es controvertido y ya se ha incidido suficientemente sobre ello, afirmar que uno de los núcleos esenciales de la actuación de los defensores es contribuir, dentro de su marco competencial y de acuerdo con sus perfiles institucionales, a que las diferentes administraciones observen y cumplan adecuadamente aquellas normas, muchas de las cuales son autoimpuestas por ellas mismas. Menos se ha llamado la atención acerca de la contribución de los defensores a la modificación de las disposiciones generales que integran el ordenamiento en el ejercicio de sus atribuciones, como mecanismo de garantía de eficacia de los derechos de los ciudadanos y de continuo desarrollo y mejora de los mismos. A este segundo aspecto de la relación defensores-normas jurídicas dedicaremos las siguientes páginas. 


\section{ESTADO SOCIAL Y PROCESOS DE INNOVACIÓN NORMATIVA}

Excede con mucho del objeto del presente artículo ni tan siquiera esbozar cuáles son las notas definitorias del Estado social postulado en el artículo 1.1 de la Constitución Española. Sí diremos, a los concretos efectos que aquí nos ocupan, que uno de los núcleos esenciales de este tipo de Estado es la atribución a los poderes públicos de la crucial misión de promover la realización efectiva del principio de igualdad material entre todos los individuos. En nuestra Carta Magna este mandato se contiene, con carácter genérico, en el artículo 9.2, precepto que dispone que

"Corresponde a los poderes públicos promover las condiciones para que la libertad y la igualdad del individuo y de los grupos en que se integra sean reales y efectivas; remover los obstáculos que impidan o dificulten su plenitud y facilitar la participación de todos los ciudadanos en la vida política, económica, cultural y social».

Como señalaba Martín Bassols, de forma casi coetánea a la constitucionalización en España de este tipo de Estado,

"el principio de igualdad real y efectiva - la garantía de la igualdad ante la ley o igualdad formal está expresa y significativamente consagrada en otro precepto constitucional (artículo 14) — es absolutamente cardinal en el esquema constitucional en cuanto determinante de la categoría de los derechos de índole social y económica, y de vinculación de los poderes públicos — con especial aplicación a la Administración Pública - a la remoción de los obstáculos que impidan o dificultan su plenitud?.

En efecto, este principio de igualdad material, ínsito de forma nuclear en la propia configuración del Estado social, determina la relevancia de los denominados derechos de contenido social o económico cuya efectividad real y universal, al menos como horizonte al que se debe tender, se convierte en presupuesto de aquel principio. Entre tales derechos, y sin ánimo de exhaustividad, se incluyen el derecho a la educación (artículo 27); al trabajo (artículo 35); a una protección social, económica y jurídica de la familia y de la infancia (artículo 39); a un régimen público de Seguridad Social (artículo 41); a la protección de la salud (artículo 43); a disfrutar de un medio ambiente adecuado (artículo 45); el derecho a una vivienda digna (artículo 47); o, en fin, la protección de la juventud, de las personas discapacitadas y de la tercera edad (artículos 48 a 50).

A estos derechos y principios rectores constitucionales cabe añadir ahora los incluidos y desarrollados en los Estatutos de Autonomía afectados por el

9 MARTÍN BASSOLS, C. "Los Principios del Estado de Derecho y su Aplicación a la Administración en la Constitución", Revista de Administración Pública, núm. 87 (Septiembre-Diciembre 1978), págs. 133 a 159 
último proceso de reforma estatutaria que ha sido llevado a cabo desde el año 2006 y que, hasta el momento, ha dado lugar a la modificación de seis Estatutos de Autonomía ${ }^{10}$. Todas estas normas estatutarias, que han sido calificadas como Estatutos de segunda generación, han recogido, con distintas formulaciones y amplitud, un catálogo de derechos y principios rectores, la gran mayoría de los cuales tiene un marcado contenido social ${ }^{11}$.

Sin duda, esta caracterización del Estado social se proyecta directamente sobre la administración pública, determinando ineludiblemente su configuración y objetivos, puesto que la actuación desarrollada por aquella se erige en un elemento esencial para fijar, a través de su desarrollo normativo, los perfiles concretos de aquellos derechos y para instrumentar los medios necesarios para garantizar su efectividad real. En concreto, se ha señalado que, de entre los diferentes modelos de administración posibles, al Estado social le corresponde una administración finalista o instrumental, en la cual, dado el carácter predominante de los derechos sociales, prevalece su carácter de instrumento al servicio del cumplimiento de los objetivos y fines que aquellos derechos de contenido social o económico implican ${ }^{12}$.

En cualquier caso, si hemos afirmado que las notas definitorias del Estado social predeterminan la actuación de la administración que desarrolla su función en el mismo, procede precisar que lo hace con toda la amplitud posible y sobre toda ella. Es decir, la esencia del Estado social no solo se limita

10 Las seis Comunidades Autónomas afectadas, hasta la fecha, por estas reformas estatutarias son, por orden cronológico de aprobación de la norma correspondiente, las siguientes: Comunidad Valenciana (Ley Orgánica 1/2006, de 10 de abril); Cataluña (Ley Orgánica 6/2006, de 19 de julio); Baleares (Ley Orgánica 1/2007, de 28 de febrero); Andalucía (Ley Orgánica 2/2007, de 19 de marzo); Aragón (Ley Orgánica 5/2007, de 20 de abril), y Castilla y León (Ley Orgánica $14 / 2007$, de 30 de noviembre).

Un análisis general de esta cuestión, con especial referencia a la Comunidad de Castilla y León, se encuentra en SEIJAS VILLADANGOS, E., "Derechos de los castellanos y leoneses (análisis de la regulación de derechos del Estatuto de Autonomía de Castilla y León)", en la obra colectiva Derechos y principios rectores en los Estatutos de Autonomía, APARICIO PÉREZ, M.A., CASTELLÀ I ANDREU J.M., EXPÓSITO, E. (coord.), Barcelona, Atelier, 2008, págs. 287-322.

11 En las Sentencias del Tribunal Constitucional 247/2007, de 12 de diciembre, y 249/2007, de 13 de diciembre, a través de las cuales se resolvieron dos recursos de inconstitucionalidad interpuestos contra el art. 20 de la Ley Orgánica 1/2006, de 10 de abril, de Reforma del Estatuto de Autonomía de la Comunidad Valenciana, se plasmó una doctrina inicial de aquel relativa a la inclusión de declaraciones de derechos en los Estatutos de Autonomía, así como a su contenido y alcance. En resumen, el Tribunal Constitucional ha señalado en aquellas sentencis que, si bien los Estatutos de Autonomía pueden incluir declaraciones de derechos, estos, con independencia da la literalidad en que sean recogidos en los preceptos estatutarios, deben ser entendidos como mandatos o directrices dirigidos a los poderes públicos autonómicos, precisando de desarrollo legislativo para adquirir plena eficacia y no pudiendo fundamentar, por sí mismos, acciones judiciales que precisen su defensa. Esta doctrina ha sido confirmada en la Sentencia 31/2010, de 28 de junio, que resolvió el recurso de inconstitucionalidad impuesto por el Grupo Parlamentario Popular del Congreso contra diversos preceptos del Estatuto de Autonomía de Cataluña (fundamento jurídico 16).

12 En este sentido, PORRAS NADALES, A.J., "La institución del Ombudsman en una democracia participativa ante el burocratismo y los poderes exorbitantes de las administraciones públicas", en El Ararteko: Un Ombudsman para el Siglo XXI, XXV Cursos de Verano en San Sebastián, 2006, págs. 242-243 y 254 . 
a influir directamente en la intervención de las administraciones públicas a la hora de aplicar a la realidad las normas que integran el ordenamiento jurídicoadministrativo, sino que también lo hace respecto a la labor que la misma administración, de forma inmediata o mediata, desarrolla en la creación y modificación de aquellas normas. En consecuencia, siendo estas administraciones los sujetos supervisados por los defensores con el fin de cumplir su función institucional de defensa de los derechos de las personas, las influencias directas que el Estado social tiene sobre la administración propia del mismo (en especial, sobre su dimensión normativa), se trasladan también como una correa de transmisión a la actuación que debe ser llevada a cabo por los defensores del pueblo en orden a cumplir eficazmente la misión que tienen encomendada. A continuación, vamos a examinar con más detalle estas cuestiones.

\section{A) Protagonismo de las administraciones públicas En El PROCESO DE PRODUCCIÓN DE NORMAS JURÍDICAS}

El fenómeno de la proliferación normativa derivada de la multiplicidad de fuentes y causado por la progresiva complejidad de las relaciones a regular no es nuevo de esta época. Aun cuando nos podríamos remontar más atrás en el tiempo, baste detenerse en la mitad del siglo XIX, cuando Ramón Ortiz de Zárate afirmaba lo siguiente en relación con esta cuestión:

"nuestra imperfecta legislación es un confuso laberinto, en que apenas es dado ni aun a fuerza del más ímprobo estudio, ni del más constante ejercido, ni de un esclarecido ingenio, conseguir altos objetivos para que ha sido establecida la justicia " ${ }^{13}$.

No obstante, es evidente que aquel embrollo o maraña legislativa no ha hecho desde entonces sino incrementarse y enredarse aún más, alcanzando niveles prácticamente inasumibles para cualquier estudioso del derecho, no digamos ya para un ciudadano profano en la materia. El desarrollo del welfarismo o Estado del bienestar ha jugado un papel importante en este proceso constante de crecimiento de la presencia de las normas jurídicas en la realidad diaria de todos. La legislación motorizada (motorisierte Gesetzgebung), a la que ya se refería Carl Schmitt en el siglo pasado ${ }^{14}$, ha funcionado sin descanso, operando el intervensionismo público propio de aquel tipo de Estado como efecto multiplicador del número de normas destinadas a regular las re-

13 Análisis Histórico-Crítico de la Legislación Española, Vitoria, 1844.

14 SCHMITT, C., Die Lage der europäische Rechtswissenshaft, Tübingen, Internat. Univ.-Verlag, 1950, pág. 20, obra citada en CORDERO QUINCARAZA, E., "El sentido actual del dominio legal y la potestad reglamentaria", Revista de Derecho de la Pontificia Universidad Católica de Valparaíso XXXII, Valparaíso, Chile, primer semestre de 2009, págs. 409-440. 
laciones jurídicas, con especial incidencia en las jurídico-públicas. La cada vez mayor relevancia cuantitativa y cualitativa de la actividad de las administraciones públicas fue precisando un armazón jurídico complejo que, de un lado, dotara a estas de los instrumentos necesarios para desarrollar su actividad, y, de otro, garantizara a los ciudadanos unos derechos básicos frente a los poderes exorbitantes reconocidos a los sujetos públicos para el cumplimiento de sus objetivos.

En el caso concreto español, al desarrollo del Estado social, se añade el proceso de descentralización imparable diseñado por la Constitución Española, proceso que generó la diversificación de instancias territoriales cuyos órganos legislativos y ejecutivos tienen reconocidas potestades normativas. En el supuesto de España y siguiendo la senda de otros estados de nuestro entorno profundamente descentralizados, el crecimiento constante de la producción normativa se ha visto impulsado exponencialmente por la implementación del Estado autonómico, uno de cuyos efectos ha sido la multiplicación, desde un punto de vista territorial, de las instancias con facultades normativas, facultades que, por otro lado, han sido ejercidas profusamente.

Ahora bien, desde el punto de vista de la transformación del ordenamiento jurídico, no solo procede hablar de un crecimiento de las normas que lo integran, sino que también es destacable el papel protagonista que la administración pública ha asumido en el proceso de producción normativa, a través de diversas vías. Como es evidente, al referirnos aquí a la administración no lo estamos haciendo a su nivel estrictamente burocrático, sino a su esfera político-gubermanental, en la cual residen las facultades normativas que la Constitución y los Estatutos de Autonomía atribuyen al poder ejecutivo. Esta circunstancia no nos aleja del objetivo central de este trabajo, puesto que no es controvertido que este nivel político-gubernamental de la administración integra el ámbito subjetivo objeto de supervisión por parte de los defensores del pueblo en su función de defensa de los derechos de los ciudadanos.

Es obvio que la forma a través de la cual las administraciones públicas han ejercido de una manera más intensa esta labor de impulso cuantitativo de la realidad normativa, ha sido mediante el ejercicio de la potestad reglamentaria. Efectivamente, el ejercicio de esta concreta potestad materialmente legislativa, atribuida al Gobierno en el artículo 97 de la Constitución, trata de responder a los procesos acelerados de cambio social y económico que demandan proporcionar una respuesta normativa rápida y eficaz, siempre en el marco de lo dispuesto en las normas de rango formalmente lega ${ }^{15}$. Lo mismo puede afirmarse del resto de instancias territoriales (autonómicas y locales) que tienen atribuida esta misma potestad, siendo destacable, en este sentido, el intenso ejercicio de esta potestad reglamentaria llevado a cabo por los ór-

15 A modo de ejemplo, podemos señalar que en el Boletín Oficial del Estado de 8 de enero de 2010 se publicó el Real Decreto 2.031 del año anterior. Aunque no todos los Reales Decretos incluyen normas jurídicas, se debe tener en cuenta que muchas órdenes ministeriales, cuyo volumen es ingente, sí que contienen, por el contrario, disposiciones de carácter general. 
ganos ejecutivos correspondientes de las Comunidades Autónomas. Lo anterior no es extraño si consideramos adecuadamente que, entre otros aspectos y de conformidad con el escenario de distribución de competencias diseñado por la Constitución primero y por los diferentes Estatutos de Autonomía después, las principales competencias relacionadas con aquellos derechos de contenido económico y social propios del Estado social corresponden a las Comunidades Autónomas.

Pero no únicamente a través del ejercicio de la potestad reglamentaria han asumido las administraciones públicas un papel principal en los procesos de innovación normativa; también en su actuación relacionada con la aprobación de normas con rango de ley el nivel político-gubernamental de la Administración participa de forma decisiva en la actividad de producción normativa.

Así, el órgano ejecutivo del Estado, mediante el ejercicio de la facultad de aprobar legislación delegada (artículo 82 de la Constitución) y disposiciones legislativas provisionales en casos de extraordinaria y urgente necesidad (artículo 87) interviene de una forma inmediata en la aprobación de normas con rango formal de ley. Estas facultades han sido también ampliadas a los diferentes órganos ejecutivos de las Comunidades Autónomas, motivo por el cual lo afirmado con anterioridad en relación con el ejercicio de la potestad reglamentaria por los órganos correspondientes de las Comunidades Autónomas puede ser reiterado aquí.

No es menos relevante la intervención que, en este caso de forma mediata, tienen el Gobierno central y los diferentes ejecutivos autonómicos en los procesos de elaboración y aprobación de las leyes, en un sentido formal, es decir de las normas que son aprobadas finalmente por los órganos depositarios de la representatividad popular y que deben constituir el núcleo esencial del ordenamiento jurídico de rango infraconstitucional. En este sentido, el ejercicio de la iniciativa legislativa reconocida al Gobierno en el artículo 87. 1 de la Constitución y en los diferentes Estatutos de Autonomía a los correspondientes órganos ejecutivos con sus distintas denominaciones, ha adquirido un papel predominante, quizás demasiado predominante, en el origen de los textos legales sometidos después a debate en el órgano legislativo correspondiente ${ }^{16}$. Igualmente, de conformidad con lo previsto en el apartado segundo del artículo 87, también las asambleas de las Comunidades Autónomas pueden solicitar al Gobierno que ejerza su iniciativa legislativa, adoptando un proyecto de ley ${ }^{17}$.

16 Baste señalar que de las catorce leyes aprobadas por las Cortes Generales en los cuatro primeros meses del año 2010, trece tuvieron su origen en proyectos de Ley aprobados por el Gobierno. Únicamente la Ley Orgánica 1/2010, de 19 de febrero, de modificación de las leyes orgánicas del Tribunal Constitucional y del Poder Judicial tuvo su origen en una Proposición de Ley presentada por el Parlamento Vasco.

17 Como es conocido, apenas si existen previsiones similares en el derecho constitucional comparado. En los debates constituyentes se llegó a afirmar que no existía ninguno, lo que no es del todo correcto, puesto que, en los que se refiere a los países de nuestra área, el artículo 121 de 
Lo anterior, en modo alguno, pone en tela de juicio la función última y primordial que reside en los parlamentos de discutir y aprobar las leyes, pero apunta a un excesivo protagonismo de la administración en el proceso que da origen a aquellos textos legales. Considerando la transversalidad de los partidos políticos en la estructura institucional diseñada por la Constitución, aquel papel principal del poder ejecutivo en el impulso del proceso legislativo apunta a una leve perversión del sistema ${ }^{18}$.

Por tanto, la presencia en primer plano de las administraciones públicas en la creación y modificación de las normas jurídicas no ha hecho más que crecer exponencialmente en las últimas décadas, quizás en exceso, circunstancia que no puede ser ajena a unas instituciones, como son los defensores del pueblo, cuya función fundamental es, precisamente, supervisar la actuación de aquellas.

\section{B) Ampliación del Ámbito de ACTuación de los DEFENSORES Del PUeblo EN EL ESTADO SOCIAL}

Ya es un lugar común señalar que la defensa de los denominados derechos sociales se configura como uno de los elementos esenciales de la función de los defensores ${ }^{19}$. En efecto, la vinculación de estos derechos con el

la Constitución italiana, de 22 de diciembre de 1947, ya recogía un supuesto similar, aunque con menor extensión. También lo hacía la, entonces vigente, Constitución de la U.R.S.S. En su artículo 113 (después, artículo 114, tras las reformas impulsadas por M.S. Gorbachev). En la actualidad, la Constitución de la Federación rusa, en su artículo 104.1, contempla la iniciativa legislativa de los distintos miembros de la Federación.

Aunque sea adelantarnos al contenido de otro punto del presente trabajo, podemos señalar aquí, como ejemplo de actuación de un defensor dirigida a proponer a los órganos de una Comunidad Autónoma el ejercicio de la iniciativa legislativa prevista en el artículo 87.2 de la Constitución, la llevada a cabo en 2004 por el Procurador del Común de Castilla y León al dirigirse de oficio a la Cortes de Castilla y León poniendo de manifiesto a estas la necesidad de que las prestaciones económicas reconocidas por las Comunidades Autónomas a quienes habían sufrido prisión durante la Guerra Civil y en la Dictadura posterior por alguno de los motivos previstos en la Ley 46/1977, de 15 de octubre, de Amnistía, fueran declaradas exentas a los efectos del Impuesto sobre la Renta de las Personas Físicas, modificando, si ello fuera necesario, su Ley Reguladora, con el fin de que el órgano legislativo autonómica ejerciera, si lo estimaba oportuno, la facultad reconocida en el artículo de la Constitución citado (Informe del Procurador del Común 2004, publicado en el Boletín Oficial de las Cortes de Castilla y León núm. 157, de 19 de mayo de 2005). Esta exención fue incorporada finalmente en el artículo 8 de la Ley 52/2007, de 26 de diciembre, por la que se reconocen y amplían derechos y se establecen medidas a favor de quienes padecieron persecución o violencia durante la guerra civil y la dictadura.

18 Por este y otros motivos no faltan quienes han puesto de manifiesto un creciente proceso de degradación de la ley parlamentaria. En este sentido, FUERTES, M., "Once tesis y una premática para restablecer la dignidad de la ley". Revista de Administración Pública, núm. 177, septiembre / diciembre, 2008.

19 Se ha hecho referencia a esta cuestión en GARCÍA ÁLVAREZ, M. y GARCÍA LÓPEZ, R., "El Modelo de Estado Social ante la Reforma de los Estatutos de Autonomía: Reconocimiento y Garantía Institucional de los Derechos Sociales", Revista Jurídica de Castilla y León, número monográfico La Reforma de los Estatutos de Autonomía, 2006, pág. 401. 
principio de igualdad material al que antes hacíamos referencia y la especial atención que los defensores deben prestar, precisamente, a los colectivos que se encuentran en riesgo de exclusión y que mayores obstáculos deben afrontar para acceder al disfrute de aquellos, hacen que sea en el ámbito de los derechos de contenido social donde estas instituciones despliegan una mayor actividad, en especial en relación con las personas singularmente desfavorecidas. Por este motivo, el desarrollo de estos derechos en un Estado social como el nuestro y las nuevas dimensiones de la actividad, normativa y ejecutiva, desplegada por las administraciones públicas para garantizar la eficacia de aquellos, dotan de un nuevo horizonte a la configuración y actuación de los comisionados parlamentarios.

En un plano teórico, se puede discutir acerca del mayor o menor grado de fundamentalidad de los denominados derechos sociales ${ }^{20}$, pero lo que no se puede poner en duda es su crucial relevancia en la sociedad actual, debido en gran parte a su estrecha vinculación con valores constitucionales de primer orden como el desarrollo integral de la persona, su dignidad o la calidad de vida. En efecto, se puede teorizar sobre si son derechos fundamentales o no en un sentido estricto, pero lo que es innegable es que son derechos esenciales para el individuo en la sociedad actual ${ }^{21}$.

Por otro lado, desde el punto de vista de la dogmática de los derechos, la propia estructura de los derechos sociales también condiciona las actuaciones dirigidas a su defensa. En este sentido, el concepto de garantía de los derechos, tal y como se entiende desde un punto de vista clásico, se encuentra más vinculado a los denominados derechos individuales o de libertad según la clasificación clásica de derechos ${ }^{22}$. Este concepto de garantía implica fundamentalmente un límite negativo, siendo el medio más idóneo para reaccionar frente a su transgresión el judicial. Sin embargo, en el caso de los derechos sociales se impone más una lógica de eficacia que de garantía, puesto que su realización efectiva implica una actuación positiva de los poderes públicos, siendo, en consecuencia, la vía necesaria para su implementación, no la propia del ámbito judicial, sino la correspondiente al nivel ejecutivo o de administración ${ }^{23}$.

Pero se puede añadir además que, desde un punto de vista normativo, los derechos sociales, de bienestar o de prestación (fundamentalmente inte-

20 En torno a la diferente fundamentalidad de los derechos, BASTIDA FREIJEDO. F.J., "Concepto y modelos históricos de los derechos fundamentales" en Teoría General de los derechos fundamentales en la Constitución española de 1978, Madrid, Tecnos, 2004, págs. 17-44.

21 En este sentido, RUIZ RICO, G., "Posibilidades que plantea el proceso de reforma estatutaria en relación con la garantía y tutela de los derechos sociales", en Jornadas sobre reformas estatutarias, derechos sociales y defensores del pueblo autonómicos, Baeza, Defensor del Pueblo Andaluz, mayo de 2005, págs. 130-131.

22 Acerca de la evolución de los derechos fundamentales, PÉREZ LUÑO, A., Los derechos fundamentales, Madrid, Tecnos, 1988 (3. ${ }^{a}$ ed.), págs. 19-51.

$23 \mathrm{Al}$ respecto, PORRAS NADALES, A.J., "Los Defensores del Pueblo ante la Reforma de los Estatutos de Autonomía", en Jornadas sobre reformas estatutarias, derechos sociales y defensores del pueblo autonómicos, Baeza, Defensor del Pueblo Andaluz, mayo de 2005, pág. 32. 
grados dentro de los principios rectores de la política social y económica enunciados en el Capítulo III del Título I de la Constitución Española, y ahora también en los nuevos Estatutos de Autonomía, como hemos visto), son derechos que deben ser desarrollados normativamente, de forma tal que el ordenamiento jurídico ha de contemplar los medios y mecanismos suficientes para garantizar su eficacia.

Los elementos descritos, relevancia de los derechos sociales en nuestro sistema político-constitucional y especial intervención de la administración para hacer efectivo su disfrute real, motivan que los defensores del pueblo asuman un papel principal, más intenso que si de defender los derechos clásicos de libertad se tratara, en orden a contribuir a garantizar su efectividad ${ }^{24}$. $\mathrm{Si}$, como hemos señalado, la eficacia de este concreto tipo de derechos se encuentra también vinculada al desarrollo normativo que los mismos obtengan, se puede afirmar que la labor de los defensores debe extenderse a la forma en la cual las administraciones abordan aquel desarrollo y lo llevan a cabo.

$\mathrm{Al}$ respecto, se puede vislumbrar que las competencias de autogobierno de las Comunidades Autónomas no son el factor exclusivo que explica la creación de los defensores autonómicos, sino que estos también pueden tener su origen en la necesidad de supervisar una pluralidad de poderes públicos que no solo aplican el ordenamiento jurídico, sino que lo innovan constantemente. No olvidemos que hemos puesto de manifiesto que la eficacia de los derechos con un carácter predominantemente social, ámbito en el cual se desenvuelve principalmente la actuación de los defensores, depende también de aquel desarrollo normativo.

Es cierto, como señala Rovira Viñas, que los ombudsman son necesarios "porque los ciudadanos, cada día en mayor medida, se ven obligados a abrirse paso ante un bosque no solo de leyes, sino también de disposiciones nacionales e internacionales complejas y en algunos casos alejadas del fin que las justificó, ${ }^{25}$. Ahora bien, los defensores al transitar este camino a través de la realidad normativa al lado de los ciudadanos no deben olvidar el papel esencial que, en la actualidad, desempeñan las administraciones que supervisan y a las que realizan recomendaciones y sugerencias en la elaboración, aprobación y modificación de muchas de las normas jurídicas que forman aquel tupido bosque jurídico.

En consecuencia, puesto que la eficacia real de los derechos de contenido social y económico constituyen un presupuesto del principio de igualdad

24 A este destacado papel de los defensores ya se hacía referencia en la exposición de motivos de la Ley 3/1985, de 27 de febrero, del Ararteko vasco, donde se señala expresamente que esta Institución "se acomoda claramente a la evolución del Estado social y democrático de Derecho y a las deficiencias que éste ha demostrado de su pretensión garantista de los derechos y libertades que van más allá de la pura declaración formal de los derechos individuales y que configura a los derechos sociales y a las libertades reales (artículo 9.2 del EAPV) como auténticas obligaciones de los poderes públicos".

25 ROVIRA VIÑAS, A., "Veinte años del Defensor del Pueblo", Revista de Derecho Político, núms. 58-59 (2003-2004), UNED, pág.363. 
material, elemento medular del Estado social, y dado que la intervención de las administraciones, tanto en su aspecto normativo como ejecutivo, en orden a la realización efectiva de aquellos constituye el núcleo esencial de la labor desarrollada por los defensores del pueblo, se puede hablar de una cierta ampliación fáctica de sus funciones, extendiéndose ahora estas a tratar de garantizar que las administraciones respondan adecuadamente a las exigencias de eficacia de estos derechos que demanda la plena implantación de un Estado social. Esta ampliación, a los efectos que aquí nos interesan, debe proyectarse sobre las funciones normativas de la administración, de cuyo correcto ejercicio también depende en gran medida que el reconocimiento de aquellos derechos sea real para todas las personas, con especial atención a aquellas que integran colectivos especialmente desfavorecidos o en riesgo de exclusión.

\section{INTERVENCIÓN DE LOS DEFENSORES DEL PUEBLO EN LOS PROCESOS DE CAMBIO NORMATIVO}

El ombudsman puede intervenir en el proceso de modificación de las normas jurídicas utilizando diversas vías. Aquí nos vamos a detener exclusivamente en la participación de los defensores en los cambios que se producen en el ordenamiento jurídico, y en especial en el ordenamiento jurídico-administrativo, a través de las recomendaciones y sugerencias formuladas por aquellos a las administraciones públicas sujetas a su supervisión como consecuencia de la tramitación de las quejas presentadas por los ciudadanos o tras el desarrollo de actuaciones cuyo inicio se produce de oficio. Lo anterior no implica que esta sea la única forma a través de la cual estas instituciones intervienen o influyen en el contenido de las normas generales.

En efecto, no podemos dejar de citar aquí su intervención, en un sentido materialmente negativo, en el contenido de las normas con rango formal de ley derivada de la legitimación para interponer un recurso de inconstitucionalidad reconocida al Defensor del Pueblo en los artículos 162.1 a) de la Constitución Española, 32.1 b) de la Ley Orgánica 2/1979, de 3 de octubre, del Tribunal Constitucional, y 29 de la Ley Orgánica 3/1981, de 6 de abril, del Defensor del Pueblo. Igualmente, también las leyes reguladoras de los comisionados parlamentarios autonómicos prevén la posibilidad de que estos se dirijan a algún órgano legitimado para interponer este recurso, bien a la asamblea legislativa o al órgano colegiado ejecutivo de la Comunidad de que se trate, bien al Defensor del Pueblo. Esta posibilidad se prevé tanto para aquellos comisionados que tienen atribuida una misión específica de defensa del Estatuto de Autonomía y del ordenamiento jurídico de la Comunidad de que se trate $e^{26}$, como en otros su-

26 Esta función específica se encuentra contemplada en las leyes reguladoras del Justicia de Aragón (Ley 4/1985, de 27 de febrero: artículo 27), del Procurador del Común (Ley 2/1994, de 9 de marzo: artículo 24), del Defensor del Pueblo de Castilla-La Mancha (Ley 16/2001, de 20 de no- 
puestos donde el defensor autonómico no tiene atribuida en su ley reguladora esta función concreta ${ }^{27}$.

Así mismo, existe otro cauce de participación informal en el proceso legislativo que en ocasiones es utilizado por los defensores, puesto que no es inusual que los órganos competentes de las administraciones públicas para tramitar los anteproyectos de ley o proyectos de decretos u órdenes remitan unos y otros a los defensores en el trámite de información pública, solicitando a estos que realicen las alegaciones que estimen oportunas a aquellos textos. Se trata de una intervención que no se encuentra recogida normativamente, quedando a juicio de los titulares de las instituciones que nos ocupan decidir si procede realizar las alegaciones solicitadas o, por el contrario, declinar poner objeciones o formular sugerencias al texto de que se trate. Normalmente, los proyectos normativos que son remitidos por las administraciones suelen, o bien regular materias especialmente relacionadas con las funciones desempeñadas por los defensores (como, por ejemplo, las que reconocen derechos de dimensión social a colectivos merecedores de especial protección o las relativas a las relaciones de los ciudadanos con las administraciones), o bien referirse a asuntos sobre los cuales haya existido una actuación previa del defensor activa e intensa.

En cualquier caso, reiteramos que aquí vamos a detenernos en la posibilidad de los defensores de recomendar o sugerir a las administraciones actuaciones de contenido normativo que pueden ser objeto de traslado después al texto finalmente aprobado de la norma jurídica de que se trate. Como veremos a continuación, esta singular actuación del ombudsman se encuentra expresamente reconocida en el ámbito internacional, estatal y autonómico, y, de hecho, ya ha tenido una traslación nada desdeñable a la realidad normativa.

\section{A) Breves notas DE DERECHO COMPARADO}

En primer lugar, en el ámbito continental europeo es ineludible citar el caso del Médiateur francés que tiene expresamente prevista en su ley reguladora la función de propuesta de modificación de textos normativos. En efecto, el artículo 9 de la Ley 6/1991, de 9 de abril, que regula su Estatuto dispone lo siguiente:

viembre: artículo 30)) y del Defensor del Pueblo Riojano (Ley 6/2006, de 2 de mayo: artículo 29). Cabe señalar que, a diferencia de lo ocurrido con el nuevo Estatuto de Autonomía de Aragón, el artículo dedicado a la Institución del Procurador del Común en la reforma del Estatuto de Autonomía de Castilla y León no hace referencia a esta función específica de defensa del Estatuto y del ordenamiento jurídico de esta Comunidad, motivo por el cual surgen dudas acerca de su mantenimiento actual.

27 Por ejemplo, en el caso del Defensor del Pueblo de Navarra (Ley Foral 4/2000, de 3 de julio, artículo 39 a)), o del Defensor del Pueblo de Murcia (Ley 6/2008, de 20 de noviembre, artículo 33). 
"Cuando el Médiateur de la République considere, ante una reclamación que le han sometido, que la aplicación de disposiciones legislativas o reglamentarias acarrea una inequidad, podrá recomendar al organismo al organismo cuestionado cualquier solución que permita resolver con equidad la situación del reclamante, proponer a la autoridad competente cualquier medida que juzgue pertinente para remediar el problema, y sugerir las recomendaciones que le parezca conveniente añadir a textos legislativos o reglamentarios".

Sin perjuicio de las notas que, hasta la fecha ${ }^{28}$, diferencian a esta figura del modelo clásico de ombudsman, como su nombramiento por el Presidente de la República, lo cierto es que tiene reconocida expresamente la posibilidad de hacer propuestas de modificación normativa y que puede hacerlo con base en el principio de equidad. En este sentido, señalaba el que fuera Defensor del Pueblo, Álvaro Gil-Robles y Gil Delgado, que

"el Mediador francés ha sido el primero que ha hecho un gran esfuerzo de análisis sobre la equidad como instrumento de trabajo del Ombudsman (...). Yo era de los que creía firmemente que el Defensor debía sobre todo actuar en base a criterios de legalidad estricta. Pues bien, me convencieron de que efectivamente, hay terrenos muy importantes en que puede actuar manejando el principio de equidad ${ }^{29}$.

A la utilización de parámetros diferentes al de la estricta legalidad a la hora de recomendar modificaciones normativas tendremos ocasión de referirnos más tarde.

Por su parte, es interesante la regulación que, del tema que nos ocupa, se contiene en el artículo 31.2 de la Ley federal constitucional del Defensor del Pueblo de la Federación rusa, de 26 de febrero de 1998. En aquel precepto se señala lo siguiente:

"Teniendo en cuenta los resultados del análisis de la información sobre la vulneración de derechos y libertades de los ciudadanos, y a la vista de las quejas recibidas, el Defensor del Pueblo puede: (...) 2) Dirigirse a los titulares del derecho de iniciativa legislativa, con propuestas de modificaciones y añadidos, o para colmar lagunas, en la legislación federal y en la de los miembros de la Federación rusa, en el supuesto de que el Defensor del Pueblo estime que las decisiones o actuaciones (o la ausencia de las mismas) de los órganos del Estado o de la Administración local, o de los fun-

28 Mientras se escriben estas líneas, esta figura se encuentra en pleno proceso de revisión después de que la Ley constitucional de 23 de julio de 2008 introdujera un nuevo Título XI-Bis en la Constitución de 4 de octubre de 1958, integrado por un único artículo 71-1 dedicado al Defensor de los Derechos. El pasado 3 de junio el Senado francés ha aprobado el Proyecto de Ley relativo al Defensor de los Derechos, con una clara inspiración de la configuración institucional del Defensor del Pueblo español.

29 Conferencia Filosofía del Defensor del Pueblo, pronunciada con motivo de las Jornadas El Procurador del Común: Defensor del Pueblo y Comunidades Autónomas, que tuvieron lugar en la ciudad de Valladolid los días 27 y 28 de octubre de 1994, editadas por Cortes de Castilla y León y Universidad de Valladolid, 1995, pág. 29. 
cionarios, que vulneren los derechos y libertades de los ciudadanos, son llevadas a cabo sobre la base de la legislación federal y de la de los miembros de la Federación, o como consecuencia de la existencia de lagunas en la legislación federal y en la de los miembros de la Federación; o en el caso de que la legislación contradiga las normas y principios generalmente reconocidos del Derecho Internacional y de los tratados internacionales de la Federación rusa ${ }^{30}$.

Todavía en el ámbito continental, procede referirse también al Defensor del Pueblo Europeo, figura prevista en el artículo 228 del Tratado de Funcionamiento de la Unión Europea y en la Carta Europea de Derechos Fundamentales, y cuyo Estatuto fue aprobado por Decisión 94/262/CE, del Parlamento Europeo de 9 de marzo de 1994. De conformidad con el artículo 3, apartados 6 y 7, de este Estatuto, cuando el Defensor considera que ha existido un caso de mala administración sin que se haya podido llegar a una solución amistosa se dirigirá a la unidad administrativa afectada formulando un proyecto de recomendación. Por su parte, la Institución dispone de un plazo de tres meses para enviar al Defensor un informe sobre la reclamación de que se trate. Con posterioridad, el Defensor del Pueblo Europeo procederá a remitir un informe al Parlamento europeo y a la institución afectada, pudiendo formular las recomendaciones que estime pertinentes. Entre estas recomendaciones nada impide que se incluyan propuestas de modificación de normas comunitarias, como ocurrió, por ejemplo, en el Informe Especial del Defensor del Pueblo Europeo al Parlamento Europeo relativo a su investigación de oficio sobre la existencia y el acceso público a un Código de buena conducta administrativa en las instituciones y órganos comunitarios ${ }^{31}$. En aquella ocasión se propuso la aprobación del citado Código, que fue aprobado por el Parlamento Europeo con fecha 6 de septiembre de 2001. Del mismo modo, también se recomendó a la Comisión que presentara una propuesta de Reglamento que incluyera un Código como el indicado.

Tras estos dos someros apuntes referidos al ámbito continental europeo, es conveniente señalar que esta función de sugerir la modificación de normas jurídicas también ha sido incluida, por influencia de la Ley española, a muchas defensorías y procuradurías de Iberoamérica. En efecto, buena parte de las leyes de los países latinoamericanos que regulan estas figuras trasladan de forma mimética lo previsto en el artículo 28 de la Ley Orgánica del Defensor del Pueblo que será analizado con posterioridad ${ }^{32}$.

30 En julio de este año 2010, el Defensor del Pueblo Ruso ha hecho llegar al Gobierno de la Federación una propuesta de disposición reguladora de las relaciones entre el ejecutivo y la defensoría, a los efectos, precisamente, de la puesta en práctica del citado artículo 31.2.

La traducción al castellano de la citada Ley realizada por GARCÍA ÁLVAREZ, M. se encuentra publicada en el Boletín del Instituto Europeo del Ombudsman, 1998.

31 Informe anual del Defensor del Pueblo Europeo 2000, pág. 216, asunto OI/1/98/0V, publicado en abril de 2001.

32 En este sentido, IGLESIAS GONZÁLEZ, F. Comentarios a la Ley Orgánica del Defensor del Pueblo, ROVIRA VIÑAS, A (coord.), Navarra, Aranzadi, 2002, págs. 708-711. 
No obstante, cabe diferenciar dos grupos de defensorías iberoamericanas a estos efectos: un primer grupo adopta un modelo muy cercano al del Defensor del Pueblo español; y un segundo, se centra más en las competencias de estas figuras como defensores de los derechos humanos. Son las instituciones incluidas dentro del primer grupo las que tienen recogida en su ley reguladora la posibilidad de proponer cambios en las normas jurídicas. Un ejemplo lo encontramos en el artículo 27 de la Ley núm. 24824 de 1 de diciembre de 1993 de Argentina que dispone lo siguiente:

"Límites de su competencia. El Defensor del Pueblo no es competente para modificar, sustituir o dejar sin efecto las decisiones administrativas. Sin perjuicio de ello, puede proponer la modificación de los criterios utilizados para su producción. Si como consecuencia de sus investigaciones llega al convencimiento de que el cumplimiento riguroso de una norma puede provocar situaciones injustas o perjudiciales para los administrados, puede proponer al Poder Legislativo o a la administración pública la modificación de la misma".

En una línea análoga se pueden citar la Ley Orgánica núm. 26520, de 8 de agosto de 1995, de Perú33 , por la que se crea la Defensoría del Pueblo, o la Ley núm. 1818, de 22 de diciembre de 1997, del Defensor del Pueblo de Bolivia ${ }^{34}$.

Por último, como excepción al segundo de los grupos de defensorías antes indicados, puede citarse el caso de la Ley núm. 212 de la Procuraduría para la defensa de los Derechos Humanos de 13 de diciembre de 1995 de Nicaragua $^{35}$.

\section{B) El Defensor del Pueblo de España}

Ya hemos anunciado que la Ley Orgánica 3/1981, de 6 de abril, del Defensor del Pueblo, prevé expresamente la facultad de este Comisionado de sugerir modificaciones del ordenamiento jurídico. En concreto, el artículo 28.2 de esta Ley dispone lo siguiente:

33 Su artículo 25 establece lo siguiente: «Sin embargo, si el Defensor del Pueblo llegase al convencimiento, como consecuencia de la investigación, que el cumplimento riguroso de una norma legal o de lo resuelto en un procedimiento administrativo ha de producir situaciones injustas o perjudiciales para los administrados, deberá poner el hecho en conocimiento del órgano legislativo y/o administrativo competente para que adopte las medidas oportunas".

34 El artículo 30 de esta Ley dispone: "Concluida la investigación, el Defensor del Pueblo emitirá sus decisiones mediante resoluciones motivadas y fundamentadas. Estas adoptarán la forma de recomendaciones o recordatorios de deberes legales. Las recomendaciones procederán en los siguientes casos: (...) 3. Cuando se trate de la rectificación de una norma, cuya aplicación provoque situaciones injustas y perjuicios".

35 Su artículo 45 afirma que: "Si como consecuencia de sus investigaciones llegase al convencimiento de que el cumplimiento riguroso de la norma puede provocar situaciones injustas o perjudiciales para los administrados, podrá sugerir a la Asamblea Nacional o a la administración pública la modificación de la misma”. 
"Si como consecuencia de sus investigaciones llegase al convencimiento de que el cumplimiento riguroso de la norma puede provocar situaciones injustas o perjudiciales para los administrados, podrá sugerir al órgano legislativo competente o a la Administración la modificación de la misma”.

El precepto transcrito se refiere, de forma acumulativa, a los órganos legislativos y a la Administración pública como destinatarios de la sugerencia del Defensor, lo cual parece expresar la diferencia entre leyes en sentido formal, aprobadas por el Parlamento, y disposiciones de rango reglamentario producidas en el ejercicio de la potestad reglamentaria reconocida en el artículo 97 de la Constitución ${ }^{36}$.

A pesar de la referencia directa que el precepto hace a los órganos legislativos, ya hemos visto que también el Defensor puede influir en el contenido de las normas aprobadas por estos a través de las sugerencias dirigidas a las administraciones públicas, considerando su participación determinante, en su nivel político-gubernamental, en el proceso de elaboración de una gran parte de las leyes aprobadas por las Cortes Generales.

Uno de los aspectos más destacados de este precepto es la amplitud con la que el mismo reconoce la facultad del Ombudsman estatal de proponer la innovación del ordenamiento jurídico, al establecer como presupuesto de esta intervención en el ámbito normativo la constatación de situaciones injustas o perjudiciales para los administrados. Es decir, no se establece como único presupuesto de las propuestas de modificación de normas que pueda realizar el Defensor del Pueblo una vulneración de un estricto principio de legalidad (a través, por ejemplo, de la transgresión de la jerarquía normativa), sino que se contempla la posibilidad de que aquel intervenga en orden a la producción de un cambio normativo siempre que considere que se está produciendo una situación contraria a principios generales del derecho de contenido más amplio y de perfiles más difusos, como son los de justicia material, equidad (lo cual nos remite a la figura del Médiateur francés) u oportunidad. Aunque la facultad prevista en este precepto no puede ser entendida como un cheque en blanco para el Defensor del Pueblo a la hora de proponer reformas normativas, es innegable que proporciona un amplio ámbito de decisión que, a nuestro juicio, debe ser correctamente utilizado, como tendremos ocasión de señalar más adelante.

Por otro lado, señala IGLESIAS FERNÁNDEZ, F. que la mención expresa al cumplimiento riguroso de la norma que realiza el precepto añade aquí

36 Precisamente, el único cambio que se produjo en este precepto en la tramitación parlamentaria de la proposición de Ley del Grupo Parlamentario Socialista que se encuentra en el origen de la Ley Orgánica, fue la inversión en el orden de la mención de los órganos legislativos y de la Administración. Esta modificación, en cuyo origen se encuentra la enmienda núm. 34 presentada por el Grupo centrista-UCD, parece responder a ordenar correctamente las fuentes de producción de las normas en función de su relevancia dentro del ordenamiento jurídico (primero las creadas por el poder legislativo y el resto después). Ver Boletines Oficiales de las Cortes Generales, núm. 39-I.3 de 20 de octubre de 1980, serie B, pág. 75; y núm. 39-II, de 7 de noviembre de 1980, serie B, pág. 97). 
poco o nada, puesto que, en términos legales, o concurre el supuesto de hecho que motiva la aplicación de una norma y la intervención consecuente de la Administración en el sentido previsto o no se da el citado supuesto de hecho, siendo difícil, en consecuencia, considerar la existencia de situaciones intermedias ${ }^{37}$. Al respecto, estando de acuerdo en esencia en que la mención señalada poco aporta a la hora de determinar los casos en los que el Defensor puede sugerir modificaciones normativas, sí son posibles situaciones donde el Defensor, sin llegar a pedir el cambio de una norma, puede optar por recomendar una determinada interpretación de la misma, más flexible, encontrándonos aquí, no obstante, en el caso previsto en el artículo 28.1 de la Ley Orgánica (sugerencia de modificación de los criterios utilizados para la producción de actos y resoluciones administrativas) o en el más genérico de las recomendaciones o sugerencias previstas en el artículo 30 de la misma Ley.

Para finalizar esta breve exégesis de la disposición contenida en el apartado segundo del artículo 28 de la Ley Orgánica del Defensor del Pueblo, procede indicar que el mismo autor y en la misma obra precitada, señala que la facultad recogida en este precepto se limitaría a la modificación de normas ya existentes mientras que la propuesta de aprobación ex novo de normas legales o reglamentarias, se debe realizar al amparo de la facultad reconocida en el artículo 30 de la misma Ley de recomendar o sugerir la adopción de nuevas medidas. Aunque este debate no nos parece de gran alcance (tampoco tiene mayores consecuencias que la propuesta de innovación normativa se realice al amparo de uno u otro artículo), el carácter más específicamente dirigido a las sugerencias de modificación normativa del artículo 28.2, respecto al más genérico del artículo 30 referido a todo tipo de resoluciones del Defensor (advertencias, recomendaciones, recordatorios de deberes legales y sugerencias), aconseja interpretar el término modificación de la norma empleado por el primero en un sentido amplio que incluya no solo la introducción de cambios en disposiciones ya existentes, sino también su desarrollo, la aprobación de las mismas e incluso su derogación o sustitución.

\section{B) Defensores autonómicos}

De forma general, aunque con diferente alcance, todas las leyes reguladoras de los defensores creados en las Comunidades Autónomas han reconocido la facultad de estos, en el desarrollo de su labor de protección de los derechos de los ciudadanos, de dirigir a los gobiernos y administraciones autonómicas propuestas de modificación de normas jurídicas.

En un primer grupo de estas leyes, se reproduce, íntegramente o en términos generales, el contenido del anteriormente comentado artículo 28. 2 de la Ley Orgánica del Defensor del Pueblo. Así ocurre en la Ley 9/1983, de 1 de diciembre, del Defensor del Pueblo andaluz (también en el artículo 28.2); Ley

37 IGLESIAS FERNÁNDEZ, F., op. cit., pág. 698. 
6/1984, de 5 de junio, del Valedor do Pobo (artículo 30); Ley 11/1988, de 26 de diciembre, del Síndic de Greuges valenciano (artículo 28.2); Ley 4/2000, de 3 de julio, del Defensor del Pueblo de la Comunidad de Navarra (artículo 33.2); Ley $7 / 2001$, de 31 de julio, del Diputado del Común de Canarias (artículo 36.2); y, en fin, Ley 5/2005, de 16 de diciembre, del Procurador General de Asturias (artículo 21.2 a)). A este grupo se puede añadir la Ley 1/1993, de 10 de marzo, del Síndic de Greuges de las Islas Baleares (artículo 23.3), si bien se debe hacer mención aquí al hecho de que esta figura institucional, a pesar de haber transcurrido más de diecisiete años desde la aprobación de su Ley, aún no se ha puesto en funcionamiento.

En consecuencia, respecto al comentario de los preceptos señalados y de las funciones reconocidas a los correspondientes defensores en orden a proponer modificaciones normativas, nos remitimos a lo señalado en relación con lo dispuesto en el artículo 28.2 de la Ley Orgánica del Defensor del Pueblo.

En un segundo grupo, se incluyen otras leyes de defensores autonómicos que, por el contrario, se apartan en algunos aspectos de lo dispuesto para el Defensor estatal.

Así, en primer lugar, la Ley 3/1985, de 27 de febrero, del Ararteko vasco, hace, en su artículo $11.1 \mathrm{c}$ ), una referencia a la posibilidad de este de recomendar modificaciones normativas, si bien la misma no es tan explícita como la recogida en los preceptos antes señalas. En aquel artículo se enuncian entre las competencias del Ararteko la siguiente:

"Señalar las deficiencias de la legislación formulando recomendaciones a fin de dotar a la actuación administrativa y a los servicios públicos de la necesaria objetividad y eficacia en garantía de los derechos de los administrados. Estas recomendaciones podrán dirigirse al Parlamento, Gobierno, Juntas Generales, Diputaciones Forales, Ayuntamientos o a las Entidades u Organismos a que se refiere el artículo $9.1 \mathrm{~d}$ )".

En la misma línea de la Ley vasca se sitúa la regulación del último en el tiempo de los defensores autonómicos en ponerse en funcionamiento. Efectivamente, en el artículo 14. c) de la Ley 6/2008, de 20 de noviembre, del Defensor del Pueblo de la Región de Murcia, al enumerar las competencias de este defensor, utiliza una redacción prácticamente idéntica a la de la Ley del Ararteko que se ha transcrito.

Por su parte, en la última de las leyes reguladoras de los comisionados autonómicos que ha sido aprobada (Ley 24/2009, de 23 de diciembre, del Síndic de Greuges de Cataluña), se abandona la redacción de la Ley anterior reguladora de esta Institución (Ley 14/1984, de 20 de marzo $^{38}$ ), que se aproxi-

38 Con base en el texto de la Ley ahora derogada, en BARTLETT CASTELLÀ, E., El Síndic de Greuges, Valencia, Tirant Lo Blanch, 2005, hay una remisión a la definición de las recomendaciones, como propuestas de modificación normativa, que se daba en el Informe Anual 1997 del Síndic y que era la siguiente: «la resolució mitjançant la cual es posa de manifest a l’Administració o a l'òrgan legislatiu competent-directament mitjançant un altre Comissionat parlamentari- la con- 
maba a la del reiterado artículo 28.2 de la Ley Orgánica del Defensor del Pueblo), y se reconoce expresamente y en dos artículos ( 4 h) y 46.2 c)), la posibilidad del Síndic no solo de pedir la modificación de una norma, sino también la aprobación de una nueva disposición normativa ${ }^{39}$.

En tercer lugar, vamos a referirnos a las leyes que atribuyen a los defensores autonómicos una específica función de defensa del Estatuto de Autonomía y del ordenamiento jurídico. En estas normas (Ley 4/1985, de 27 de junio, del Justicia de Aragón; Ley 2/1994, de 9 de marzo, del Procurador del Común de Castilla y León; Ley 16/2001, de 20 de diciembre, del Defensor del Pueblo de Castilla-La Mancha; y, en fin, Ley 6/2006, de 2 de mayo, del Defensor del Pueblo de la Rioja), junto a referencias realizadas a la facultad de recomendar modificaciones de disposiciones generales como las hasta aquí citadas, se incluyen previsiones específicas referidas a la propuesta de innovación normativa en el ejercicio de aquella concreta atribución.

A modo de ejemplo, podemos citar las previsiones contempladas al respecto en la Ley reguladora del Justicia de Aragón, cuya función de defensa del Estatuto y del ordenamiento ha sido elevada a rango estatutario como se ha señalado con anterioridad. Así, en primer lugar, el artículo 22.4 de esta Ley señala que "si la aplicación de una norma legitimamente acordada fuera la que condujere a resultados injustos o dañosos, el Justicia podrá recomendar su modificación o derogación" (precepto genérico). Por su parte, y ya dentro de su función de defensa del Estatuto, su artículo 28 dispone que "si el Justicia juzgare que la violación del Estatuto se deriva de una acto de las Cortes de Aragón, requerirá motivadamente a estas para que lo subsanen y de no hacerlo podrá ponerlo en conocimiento del Defensor del Pueblo, sugiriéndole la medida a adoptar" (en clara referencia al recurso de inconstitucionalidad). Por último y en cuanto a su defensa del ordenamiento jurídico, el artículo 34 establece que

"Cuando el Justicia estime que algún precepto reglamentario emanado de la Diputación General de Aragón infringe el Estatuto de Autonomía o el Ordenamiento jurídico aragonés, se dirigirá motivadamente a la misma recomendando su modificación o derogación”.

De igual manera ocurre en las Leyes del Procurador del Común (artículo 20.2 con carácter genérico, y 25 y 26 en defensa del Estatuto de Autonomía y del ordenamiento jurídico ${ }^{40}$, del Defensor del Pueblo de Castilla-La Mancha

veniència de dictar una determinada norma, legal o reglamentària, o de modificar les vigents, a l’efecte d'adequar el bloc de la legalitat a la Constitució i l’Estatut déAutonomia de Catalunya, els tractats i conveniens internacionals ratificats por $1^{\prime}$ Estat espanyol, omplir un buit normatiu o eliminar una contradicció entre normes vigents" (Informe 1997, publicado en el Boletín Oficial del Parlamento Catalán, pág. 21.749).

39 Aunque, como ya hemos señalado, una interpretación amplia del artículo 28.2 de la Ley Orgánica del Defensor del Pueblo y de los preceptos de las leyes autonómicas similares al mismo, también da cabida a esta posibilidad

40 Sin perjuicio de que esta función, como ya hemos anunciado, haya desaparecido en el nuevo Estatuto de Autonomía de Castilla y León. 
(artículos 27.2; y 30 y 31, respectivamente), y, en fin, del Defensor de la Rioja (artículo 25.2 con carácter general y 36 en defensa del Estatuto de Autonomía).

En cualquier caso, lo que queda claro es que todos los defensores del pueblo, con mayor o menor amplitud, tienen reconocida en sus leyes reguladoras la posibilidad de recomendar o sugerir a los poderes públicos con competencias normativas cambios o innovaciones que se pueden trasladar al ordenamiento jurídico a través del ejercicio de estas. Se puede afirmar, por tanto, que todas las asambleas legislativas han considerado como uno de los instrumentos o vías adecuados para que los defensores ejerzan su función de supervisores de la eficacia de los derechos de los ciudadanos la propuesta de modificación o aprobación de disposiciones normativas cuando aquellos consideren que esta operación de cirugía jurídica sea necesaria con el fin de garantizar la realidad y efectividad de tales derechos para todas las personas.

\section{D) RELACIONES CON OTROS ÓRGANOS}

Los defensores del pueblo no son actores usuales en los procedimientos dirigidos a modificar las normas jurídicas: de un lado, no forman parte, como es obvio, del procedimiento formal establecido para la elaboración y aprobación de aquellas; y, de otro, su actuación hasta la fecha relacionada con los cambios normativos, como veremos más adelante, si bien no ha sido desdeñable, tampoco ha tenido la suficiente relevancia, cuantitativamente hablando, para que se pueda hablar de que su intervención en este sentido sea frecuente o usual. Por este motivo, debemos plantearnos cómo se articula la relación de los defensores con los órganos que sí intervienen de forma ordinaria en estos procedimientos de innovación normativa.

En primer lugar, se debe poner de manifiesto un hecho más que evidente: los defensores no son legisladores y, en consecuencia, sus sugerencias y recomendaciones cuyo objeto principal sea el cambio o la aprobación ex novo de una norma, por otra parte como el resto de sus resoluciones, son de aceptación facultativa para aquellos órganos en quienes recae la adopción de la decisión final, en este caso de naturaleza normativa. Aunque la afirmación anterior pueda parecer innecesaria, no está fuera de lugar traerla a colación aquí porque, precisamente, en el carácter no vinculante de sus propuestas de modificación del ordenamiento jurídico radica, aunque pueda parecer paradójico, su fuerza. En efecto, es a través de estas propuestas no vinculantes como de forma más adecuada se puede ejercer la auctoritas de los defensores que, se indicará con posterioridad, es una de las notas que, a nuestro juicio, convierten a estas figuras institucionales en especialmente adecuadas para impulsar cambios en las normas, siempre con el objetivo de mejorar la protección y eficacia de los derechos, con especial incidencia en aquellos de contenido esencialmente social. Mal podría ejercerse aquella autoridad moral si se desplazase, aun cuando fuera informalmente, el centro de decisión de los ór- 
ganos que la tienen atribuida a otros distintos, por muy reconocida que sea su aptitud para adoptar aquella decisión. En otras palabras, la posibilidad de los órganos con competencias legislativas, en sentido material, de apartarse de las propuestas de modificación normativa formuladas por los comisionados parlamentarios es una consecuencia imperativa de la propia distribución funcional entre instituciones impuesta por el marco constitucional y legislativo del que nos hemos dotado; sin embargo, esta ausencia de obligatoriedad, aunque pudiera parecer inicialmente un contrasentido, refuerza la aptitud de aquellos para realizar tales propuestas y para que las mismas tengan una fuerza moral que impone su adecuada consideración por los órganos e instituciones a quienes van dirigidas.

Más compleja es la relación con otros órganos cuya intervención material podría guardar semejanzas con la desarrollada por los defensores que aquí se está comentando, si bien desde un punto de vista formal su participación es completamente diferente. Nos estamos refiriendo aquí a aquellos órganos que, con carácter preceptivo y por establecerlo así la normativa correspondiente, deben emitir un informe con carácter previo a la formación definitiva de la voluntad del órgano con competencias para aprobar la norma o su proyecto, en el caso de que se trate de una ley orgánica u ordinaria cuya aprobación final solo puede corresponder a las Cortes Generales o a las asambleas legislativas de las Comunidades Autónomas. Se trata de órganos como el Consejo de Estado ${ }^{41}$ y los consejos consultivos autonómicos ${ }^{42}$, los consejos económicos y sociales ${ }^{43}$ o el Consejo General del Poder Judicial ${ }^{44}$.

41 La Ley Orgánica 3/1980, de 22 de abril, recoge en sus artículos 21 y 22 diversos supuestos en los que el Consejo de Estado debe ser consultado sobre diferentes textos normativos, tales como anteproyectos de leyes que hayan de dictarse en ejecución, cumplimiento o desarrollo de tratados, convenios o acuerdos internaciones o del derecho comunitario europeo (artículo 21.2), proyectos de Decretos legislativos (artículo 21.2), disposiciones reglamentarias que se dicten en ejecución, cumplimiento o desarrollo de tratados, convenios o acuerdos internacionales o del derecho comunitario europeo (artículo 22.2) o reglamentos o disposiciones de carácter general que se dicten en ejecución de leyes, así como sus modificaciones (artículo 22.3))

$42 \mathrm{Sin}$ entrar a detallar las competencias que las leyes reguladoras de los diferentes consejos consultivos creados en las Comunidades Autónomas reconocen a estos, podemos afirmar que dentro las mismas se incluye la de informar anteproyectos de leyes y proyectos de reglamentos autonómicos.

43 De conformidad con lo dispuesto en el artículo 7.1.1. de la Ley 21/1991, de 17 de junio, una de las funciones del Consejo Económico y Social estatal es emitir dictamen con carácter preceptivo sobre anteproyectos de leyes del Estado y proyectos de reales decretos legislativos que regulen materias socieconómicas y laborales y proyectos de reales decretos que se considere por el Gobierno que tienen una especial trascendencia en la regulación de las citadas materias (artículo 7.1.1 a). Al igual que ocurría en el caso de los consejos consultivos creados por las Comunidades Autónomas también en el supuesto de los consejos económicos y sociales creados por estas se ha producido un traslado mimético a los mismos de esta intervención en el proceso de aprobación de determinadas disposiciones generales)

44 De acuerdo con lo dispuesto en el artículo 108.1 de la Ley Orgánica 6/1985, de 1 de julio, el Consejo General del Poder Judicial deberá informar los anteproyectos de leyes y disposiciones generales del Estado y de las Comunidades Autónomas que afecten total o parcialmente a las materias que se relacionan en el precepto 
En concreto, podría plantearse una posible colisión entre la función de los defensores que aquí venimos comentando y la encomendada, con un ámbito general, al Consejo de Estado y a los consejos consultivos autonómicos, como supremos órganos consultivos de las administraciones estatal y autonómicas, respectivamente. Sin embargo, las diferencias entre la intervención de los defensores y la de los consejos consultivos en los procesos de modificación normativa impiden hablar de un solapamiento entre funciones institucionales, revistiendo aquellas diferencias tanto un carácter formal como material.

Así, desde una perspectiva formal, mientras los órganos consultivos señalados tienen atribuido en la normativa aplicable un papel de informantes en los procedimientos de aprobación o modificación de normas reglamentarias o proyectos de normas legales, no ocurre lo mismo con los defensores, quienes adoptarán la decisión de proponer una modificación normativa cuando, tras el desarrollo de su actuación a instancia de los ciudadanos (como consecuencia de las quejas presentadas por estos) o de oficio, considere que la mejor forma de proteger la eficacia general de un derecho sea la modificación de una norma que afecte a su contenido o la aprobación de una nueva que lo desarrolle. Esta diferencia formal hace que la intervención de unas y otras instituciones se produzca en momentos diferentes del procedimiento de modificación normativa, puesto que mientras los consejos consultivos se pronuncian sobre un proyecto de texto normativo, los defensores lo pueden hacer en relación con la conveniencia o necesidad de la modificación cuando la misma no ha nacido, ni tan siquiera de forma embrionaria ${ }^{45}$.

Desde un punto de vista material, el informe o dictamen emitido por los consejos consultivos tiene como objeto fundamental informar sobre los aspectos de legalidad que se pueden plantear a la vista del texto sometido a su dictamen. Por el contrario, cuando los defensores estiman conveniente sugerir una modificación normativa pueden utilizar para alcanzar esa conclusión, no sólo criterios de estricta legalidad, sino también elementos de justicia material o de equidad que apoyen su decisión. En este sentido, ya hemos señalado que la gran mayoría de las leyes que recogen esta función de los defensores se refieren a la constatación de situaciones injustas o perjudiciales como presupuesto de la decisión de los comisionados de proponer cambios en las normas jurídicas. En consecuencia, el ámbito de decisión del que disponen los defensores a la hora de impulsar, en el marco de sus funciones,

45 Cuestión diferente es cuando el Consejo de Estado emite, a petición del Gobierno, informes acerca de cuestiones generales (como, por ejemplo, el emitido con fecha 24 de febrero de 2009 acerca de la posible modificación del régimen electoral general), en los cuales pueden realizarse propuestas de carácter normativo. En este caso las similitudes con las propuestas realizadas por los defensores crecen desde este punto de vista formal. En un sentido contrario, también se acerca la intervención de los defensores a la llevada a cabo por los consejos consultivos cuando aquellos formulan alegaciones en el trámite de información pública al que se somete todo proyecto normativo, en ocasiones previa petición del órgano correspondiente de la Administración. 
una reforma normativa es más amplio que aquel del que disponen los consejos consultivos cuando tienen que emitir sus dictámenes a la vista de los textos sometidos a su consulta por la Administración. Todo ello, sin olvidar que el fin último de la labor de los defensores, también cuando de lo que se trata es de proponer innovaciones en el ordenamiento jurídico, no es otro que defender los derechos de los ciudadanos y tratar de garantizar el cumplimiento de los principios que deben presidir las relaciones entre aquellos y las administraciones públicas, circunstancia esta última que también les aleja de la función propia de los órganos consultivos.

En definitiva, ni los defensores del pueblo tienen la capacidad de imponer la aprobación o modificación de una norma, ni sus propuestas de cambios normativos se solapan con la función propia atribuida en este ámbito a otros órganos, en especial a los consejos consultivos. Por tanto, el ejercicio de esta facultad reconocida en las distintas leyes reguladoras de los defensores, no solo no introduce distorsión alguna en el diseño de los procedimientos de aprobación de leyes y reglamentos, sino que puede contribuir notablemente a mejorar el resultado final de los mismos.

\section{E) TRAsCendencia PRÁCTICA}

Como se ha puesto de manifiesto la función de proponer modificaciones normativas se encuentra recogida en la totalidad de las leyes reguladoras de los defensores del pueblo. Pues bien, no se puede afirmar que estos no la hayan utilizado. Cuestión distinta es que sea conveniente hacer un llamamiento para que, en cualquier caso, estas instituciones consideren como un instrumento especialmente adecuado para promover la protección y mejora de la eficacia de los derechos a cuya defensa se consagran la formulación de propuestas de reforma de normas jurídicas cuando con la misma se garantice o se contribuya a lograr aquel fin.

No sería posible realizar aquí un repaso completo a todas las ocasiones en las que los defensores han propuesto cambios de normas ${ }^{46}$. Por este mo-

46 De una simple lectura de la relación de recomendaciones y sugerencias formuladas por el Defensor del Pueblo en 2008 podemos extraer, entre otras y a modo de ejemplo, las siguientes cuyo contenido incluye una propuesta de modificación normativa: Recomendación 2/2008, de 14 de enero, sobre propuesta de regulación de medidas correctoras de la repercusión del aumento del valor inmobiliario para la tercera edad y colectivos en situaciones de especial protección; Recomendación 10/2008, de 15 de febrero, para que se modifique la Orden PRE/1283/2007, de 10 de mayo, sobre emisión de cartas de invitación, suprimiendo la exigencia de comparecencia personal del solicitante y la aportación del certificado del presidente de la comunidad de la vivienda destinada al alojamiento; Recomendación 62/2008, de 3 de julio, para que se regule el régimen de disciplina académica de las universidades, con el fin de que estas puedan desarrollar las normas sobre derechos y deberes de sus estudiantes, y los mecanismos para sus garantías; Recomendación 63/2008, de 4 de julio, sobre el régimen jurídico de los depósitos de detenidos; o, en fin, Recomendación 74/2008, de 17 de julio, sobre modificación del procedimiento seguido en los expedientes de repatriación para garantizar el derecho de los menores a ser oídos, a la debida 
tivo, nos limitaremos a exponer un grupo de ejemplos en los que en la propia exposición de las normas legales o reglamentarias se reconoce el origen de las mismas o de una parte de ellas en la actuación del Defensor del Pueblo o de un defensor autonómico.

Así, comenzando con las normas aprobadas por una asamblea legislativa representativa, tanto estatal como autonómica, podemos enunciar, de forma ejemplificativa, las siguientes:

- Ley Orgánica 2/2009, de 11 de diciembre, de reforma de la Ley Orgánica 4/2000, de 11 de enero, sobre derechos y libertades de los extranjeros en España y su integración social: en el preámbulo de la Ley se señala que en cuanto a las modificaciones introducidas en relación con los derechos de los extranjeros (Título I de la Ley) y, en especial, con el de asistencia jurídica gratuita, se ha tenido en cuenta, no solo la jurisprudencia del Tribunal Constitucional, sino también las recomendaciones del Defensor del Pueblo ${ }^{47}$.

- Ley 18/2007, de 28 de diciembre, del derecho a la vivienda de Cataluña: se señala en su exposición de motivos que la regulación del

asistencia jurídica y a la notificación de las resoluciones que recaigan (Recomendaciones y Sugerencias 2008, Defensor del Pueblo, Madrid, 2009).

Por su parte, los defensores autonómicos también recurren a la formulación de propuestas de cambios normativos para el ejercicio de su alta función de defensa de los derechos. A modo de ejemplo, podemos señalar que el Defensor del Pueblo Andaluz en el año 2009 formuló, entre otras, las siguientes recomendaciones sobre aprobación y modificación de normas: Recomendación sobre la aprobación de una moratoria urbanística en la edificación en zonas de influencia del litoral; Recomendación sobre una nueva regulación sobre los requisitos de acceso a centros de mayores para personas dependientes y en situación de exclusión social; Recomendación acerca de la reincorporación de la acción pública en materia de cultura, modificando para ello la Ley 14/2007, de Patrimonio Histórico de Andalucía; Recomendación para que se apruebe una regulación del taxi; Recomendación sobre la regulación del derecho a la asistencia sanitaria (Informe al Parlamento 2009, publicado en el Boletín Oficial del Parlamento de Andalucía núm. 452, de 6 de mayo de 2010).

En alguna ocasión también, los defensores autonómicos, teniendo la norma cuya modificación estiman conveniente un origen estatal, se dirigen al Defensor del Pueblo para que sea a través de esta Institución como se canalice su propuesta de modificación normativa, en el marco de las debidas relaciones de coordinación entre comisionados parlamentarios. Así ocurrió, por ejemplo, en el caso del Procurador del Común de Castilla y León y en 2003, cuando se dirigió al Defensor estatal poniendo de manifiesto la conveniencia de que se modificara el artículo 171 del Código Civil, en lo relativo a la rehabilitación o prórroga de la patria potestad de incapaces. En este supuesto, el defensor estatal comunicó al autonómico que compartía el criterio expuesto por este y que iba a proceder al estudio del marco jurídico del incapaz, efectuando, en su caso, las oportunas resoluciones a los órganos implicados (Informe Anual 2003 del Procurador del Común, publicado en el Boletín Oficial de las Cortes de Castilla y León núm. 90, de 1 de septiembre de 2004).

47 En este sentido, en el año 2005 el Defensor del Pueblo presentó un Informe especial sobre asistencia jurídica a los extranjeros en España, entre cuyas recomendaciones se incluían varias dirigidas a diversos Ministerios para que estos ejercieran su iniciativa legislativa en el sentido recomendado (Informe sobre asistencia jurídica a los extranjeros en España., Madrid, Defensor del Pueblo, 2005). 
procedimiento de adjudicación de viviendas de protección oficial y del Registro de Solicitantes se lleva a cabo considerando aspectos sobre los que ha llamado la atención el Síndic de Greuges.

- Ley 12/2001, de la infancia y la adolescencia en Aragón: en el propio preámbulo de la Ley se señala que el Justicia de Aragón, y también las Cortes aragonesas, habían instado al ejecutivo aragonés la elaboración y presentación de un proyecto de ley que respondiese a un necesario carácter integral de la promoción y defensa de los derechos de los menores.

- Ley 6/1999, de 7 de julio, de atención y protección a las personas mayores en Andalucía: en la exposición de motivos de esta norma se indica que la introducción en la misma de un catálogo de derechos y deberes de los usuarios de servicios sociales y centros residenciales se realiza atendiendo a una reivindicación del Defensor del Pueblo Andaluz.

- Ley 1/1999, de 31 de mayo, de atención a las personas con discapacidad en Andalucía: en la exposición de motivos de la Ley se reconoce que se han recogido en su texto las recomendaciones contenidas en los últimos informes del Defensor del Pueblo y del Defensor del Pueblo Andaluz en relación con la situación del empleo, atención residencial de las personas con discapacidad, a la problemática de la atención a los enfermos mentales y a las barreras arquitectónicas, urbanísticas, en el transporte y en la comunicación.

Si no faltan leyes donde se reconoce el impulso de la actuación de un defensor del pueblo como origen de su elaboración y aprobación o de alguno de sus contenidos concretos, igual afirmación puede realizarse respecto a las normas de rango reglamentario. Con el mismo ánimo de enunciar algunos ejemplos, a continuación se relacionan algunas de estas disposiciones cuyo origen se encuentra relacionado con la propuesta de un defensor:

- Decretos aprobados por las Comunidades Autónomas de concesión de indemnizaciones a las personas que sufrieron prisión como consecuencia de los supuestos contemplados en la Ley 46/1977, de 15 de octubre, de Amnistía, pero no pudieron acceder a las indemnizaciones aprobadas por el Gobierno por no cumplir los requisitos exigidos para ello, en especial el período mínimo de permanencia en prisión: la posibilidad de extender los supuestos indemnizables que habían sido contemplados por el Gobierno fue apuntada por el Defensor del Pueblo a las distintas Comunidades Autónomas ${ }^{48}$.

- Decreto 140/2009, de 21 de julio, de la Comunidad de Andalucía, por el que se aprobó el Reglamento que regula las normas para la acce-

48 Así se reconoce expresamente, cuando menos, en el Decreto 186/2004,de 12 de agosto, de la Región de Murcia y en el Decreto 28/2002, de 6 de marzo, de Castilla-La Mancha, por los que se aprobaron aquellas indemnizaciones para sus respectivos ámbitos territoriales 
sibilidad en las infraestructuras, el urbanismo, la edificación y el transporte en Andalucía: en la propia exposición de motivos se indica que en la elaboración de este Decreto se consideraron las recomendaciones recogidas en los últimos informes del Defensor del Pueblo Andaluz.

- Decreto 127/2001, de 5 de junio, de medidas de seguridad en los parques infantiles en Andalucía: en el preámbulo de este Decreto se señalaba que el mismo se dirigía a cubrir una laguna normativa que había sido denunciada por el Defensor del Pueblo estatal a través de la presentación de un Informe especial sobre la materia ${ }^{49}$.

- Decreto 137/2002, de 26 de noviembre, por el que se aprobó el Reglamento de Policía Sanitaria Mortuoria de Extremadura: en su preámbulo se indica expresamente que, entre otros objetivos, la norma persigue superar las dificultades puestas de manifiesto por el Defensor del Pueblo en relación con la donación de órganos por la excesiva dilación de los trámites administrativos y judiciales necesarios.

- Real Decreto 175/2005, de 23 de julio, de modificación del Reglamento del Registro Civil: entre otros aspectos, esta norma suprime, en los supuestos de inscripción de nacimiento cuando existe una sola filiación, la obligación de la madre o del padre del menor de inventarse un progenitor falso a los solos efectos identificativos, dando cumplimiento, como expresamente se reconoce en la exposición de motivos de esta norma, a una recomendación realizada por el Defensor del Pueblo en el año 2000.

Una lectura atenta de los ejemplos indicados revela que la actuación de los defensores consistente en proponer modificaciones normativas se desarrolla con especial intensidad en el ámbito de los derechos de contenido social y con singular incidencia en aquellos grupos sociales que mayores dificultades encuentran para acceder al disfrute de los mismos con toda su amplitud y eficacia. Lo anterior es coherente con lo ya afirmado respecto a que este, el de los derechos sociales y el de las personas en riesgo de exclusión, se ha convertido en el principal, aunque no único, campo de acción de estas instituciones.

Ahora bien, no siempre es fácil determinar el grado de participación que la actuación de un defensor ha tenido en la elaboración y aprobación final de una norma o de parte de ella. No caben dudas en casos como los que han sido puestos de manifiesto con anterioridad, donde el órgano con competencias legislativas reconoce en el propio texto adoptado el carácter decisivo de la intervención del defensor. No ocurre así en otros muchos supuestos, donde la conexión entre la propuesta de cambio normativo y el texto finalmente aprobado es mucho más difícil de establecer. Vamos a verlo en un ejemplo.

49 Estudio y Recomendaciones sobre Seguridad y Prevención de Accidentes en Áreas de Juegos Infantiles, Madrid, Defensor del Pueblo, 1997. 
El Procurador del Común de Castilla y León, como el resto de defensores, en ocasiones desarrolla su labor de defensa de los derechos mediante la realización de sugerencias de modificaciones normativas dirigidas a los órganos administrativos competentes. Así ocurrió, por ejemplo, en una queja resuelta en el año 2004, en la cual se recomendó a la Administración autonómica que introdujera en la legislación de establecimientos públicos de la Comunidad una regulación del derecho de admisión ${ }^{50}$.

Por el contrario, más complejo es establecer una relación causa-efecto entre la propuesta realizada por el Procurador del Común en el año 2004 referida al establecimiento como causa de interés social, a los efectos expropiatorios, del cumplimiento de las condiciones de accesibilidad exigibles a una vivienda, y una previsión incluida en este sentido en el reciente Proyecto de Ley de Vivienda de Castilla y León. En efecto, en 2004 aquel defensor recomendó a la Administración autonómica que, en el ejercicio de su facultad de iniciativa legislativa, promoviera la inclusión de una causa de expropiación forzosa por razones de interés social para casos concretos donde, reuniendo determinadas circunstancias, fuera necesaria aquella para la ejecución de obras que hicieran accesible una vivienda. En aquel momento, la recomendación señalada no fue aceptada por la Administración destinataria de la misma. Sin embargo, recientemente se ha publicado en el Boletín Oficial de las Cortes de Castilla de León núm. 173, de 7 de septiembre de 2010, la Ley del Derecho a la Vivienda de la Comunidad de Castilla y León, donde se incluye un precepto que recoge lo recomendado en aquella ocasión por el Procurador del Común ${ }^{51}$.

En supuestos como el señalado, no es posible conocer cuánto ha tenido que ver la recomendación inicial realizada por el defensor en la elaboración de la norma reformada. No obstante, sí se puede afirmar que la propia formulación de la propuesta de reforma normativa puede generar un debate social e institucional que, pese a que en un primer momento, no fructifique en la aprobación del cambio sugerido, puede cristalizar y hacerse realidad transcurrido un tiempo más o menos prolongado.

50 Informe Anual 2003 del Procurador del Común (expediente Q/832/03). Pues bien, en la propia exposición de motivos de la Ley $7 / 2006$, de 2 de octubre, de espectáculos públicos y actividades recreativas de la Comunidad de Castilla y León, se señala que la regulación incluida en la misma del denominado derecho de admisión se realiza en consonancia con las recomendaciones realizadas por aquella Institución.

51 Se establece en el artículo 17.2 del Proyecto lo siguiente: “Cuando deban llevarse a cabo en los edificios de viviendas las obras necesarias para el cumplimiento de la normativa en materia de accesibilidad y supresión de barreras arquitectónicas, de conformidad con la legislación sectorial aplicable así como la normativa en materia de propiedad horizontal, concurrirá interés social como causa para el ejercicio de la potestad expropiatoria por la Administración local y para la urgencia a los fines expropiatorios". 


\section{LA PARTICIPACIÓN EN LA MODIFICACIÓN DEL ORDENAMIENTO JURÍDICO: UNA NUEVA DIMENSIÓN DE LA ACTUACIÓN DE LOS DEFENSORES.}

Como hemos indicado, la actuación de los defensores del pueblo dirigida a sugerir la aprobación o modificación de normas jurídicas no es desconocida para las leyes reguladoras de estas instituciones e informa el desarrollo diario de la labor encomendada por la Constitución, los Estatutos de Autonomía y las leyes a estos comisionados parlamentarios. En efecto, la totalidad de las leyes que regulan en la actualidad a estas instituciones reconocen expresamente esta facultad de sugerir cambios normativos, como un instrumento que puede ser utilizado por aquellas en su misión de defender los derechos de los ciudadanos. Así mismo, no faltan ejemplos prácticos, como se ha expuesto también, que nos permitan afirmar que el Defensor del Pueblo y los defensores autonómicos no dudan en dirigirse a los órganos con competencias normativas con el objeto de proponerles reformas en el ordenamiento cuando consideran que las mismas son convenientes para procurar más protección y mayor eficacia de los derechos que constituyen la materia prima que justifica su existencia y sobre la que deben trabajar. A lo anterior se añade la propia evolución del Estado social y del papel de la Administración en el mismo en relación con la creación y cambio de las normas que constituyen su estructura jurídica. A ello también nos hemos referido en el presente trabajo.

Ahora bien, es posible que no se haya insistido suficientemente en la relevancia que esta forma concreta de proteger los derechos puede adquirir y en las ventajas que un correcto ejercicio de la misma puede proporcionar, no solo a la eficacia real de aquellos derechos para todos, sino también a la propia calidad de las normas con las que se dota un Estado social con el fin de preservar su misma esencia: la realización de un principio de justicia material a través de la garantía del acceso universal a derechos de contenido esencialmente social. En este contexto es conveniente que los defensores adopten una postura proactiva en orden a la defensa de los derechos, orientada a detectar las exigencias derivada de una efectiva realidad de estos para todas las personas y colectivos en los que se integran, acudiendo a la reforma normativa como vía especialmente apta para manifestar esta actitud ${ }^{52}$.

52 En palabras del propio Enrique Múgica, anterior Defensor del Pueblo; «... cada vez con más frecuencia, podemos percibir un cierto clima social, acaso una invitación, para que el Defensor del Pueblo asuma con mayor firmeza la defensa los derechos de los ciudadanos sin esperar a que las agresiones o situaciones indeseables lleguen a consumarse, a hacerse evidentes. Podemos pensar por ello que, en un futuro próximo, uno de los retos principales del Defensor consistirá en adoptar una actitud distinta. Más allá de reaccionar ante las deficiencias administrativas, ha de tender a procurar una actuación determinada, una práctica administrativa conveniente. Nuestra tarea habrá de ser más que reactiva, proactiva en relación con la protección de los derechos y las libertades básicas. Es decir, tendremos que partir de un enfoque más preventivo que curativo, que puede encontrar su expresión en acciones cautelares que traten de evitar una eventual lesión de los derechos fundamentales de los ciudadanos impidiendo que esos derechos sean conculcados" 
Además de que la propia dinámica que exige la defensa de los derechos en un Estado social conduce ineludiblemente a ello, los defensores del pueblo recogen una serie de notas en su realidad institucional y en la dimensión de su actividad que les convierten en figuras especialmente aptas para impulsar modificaciones normativas y para actuar como auténticos innovadores y dinamizadores del ordenamiento jurídico. Cuatro de los aspectos que convierten la labor de impulso de los cambios en las disposiciones generales en un, sino totalmente nuevo, sí más visible y relevante horizonte de la actuación de estas instituciones son los siguientes:

\section{- La auctoritas de los defensores}

Como afirma Rovira Viñas los defensores del pueblo han venido a resucitar la vieja contraposición romana entre auctoritas y potestas. La primera, que ahora se atribuye a los defensores (han sido calificados como magistraturas de persuasión), se define no solo como el saber socialmente reconocido, sino también a través de la influencia que ejerce a quien se reconoce este saber ${ }^{53}$. La adquisición y mantenimiento de esta auctoritas se logra a través del rigor y de la valía del trabajo realizado por estas instituciones: cuanta más calidad técnica e independencia adorne la labor de los defensores mayor influencia podrán tener estos en los órganos a quienes dirigen sus resoluciones.

A los efectos que aquí nos interesan, esta capacidad de influencia en la que se debe traducir la auctoritas de los defensores tiene un campo idóneo de ejercicio en relación con el contenido de las normas jurídicas. El ámbito de decisión propio de los órganos con competencias normativas para innovar y modificar el ordenamiento jurídico es amplio y dentro del mismo las intervenciones de los defensores, revestidos de auctoritas en el sentido indicado, tienen lugar en un terreno de juego propicio para verse trasladadas a la decisión final que se adopte y al texto de la norma jurídica de que se trate. A través de esta influencia, los defensores pueden y deben actuar como dinamizadores del ordenamiento jurídico, influenciando e impulsando su evolución y la mejora continua de su calidad.

Ahora sí, al igual que ocurre con el resto de decisiones adoptadas por los defensores, su traducción real, es decir, su influencia final en los órganos con capacidad decisoria (en este caso de tipo normativo), estará condicionada por la calidad técnica y jurídica de las propuestas realizadas por aquellos, y, en lo que aquí que nos ocupa, de la capacidad de constatar de forma adecuada, fundamentalmente a través de las quejas de los ciudadanos, las necesidades reales de reforma del ordenamiento. En otras palabras, los defensores solo lograran ampliar la protección y eficacia de los derechos de los ciudadanos a

(El devenir de las defensorias en una perspectiva de futuro en El Ararteko: un Ombudsman para el Siglo XXI, XXV Cursos de Verano en San Sebastián / XVIII Cursos Europeos - UPV/EHU, 2006). 53 ROVIRA VIÑAS, A., op. cit., págs. 359 y 360. 
través de modificaciones normativas en la medida en que sean capaces de detectar los aspectos de aquel ordenamiento que deben evolucionar y ser mejorados, así como de expresar sus propuestas con unos niveles técnicos y de calidad jurídica óptimos.

\section{- La independencia de los defensores}

La posición ocupada por los defensores dentro de la arquitectura institucional constitucional y estatutaria ofrece una situación privilegiada para influir en la evolución del ordenamiento jurídico y para impulsar sus cambios. Ya se ha hecho hincapié en que la nota de independencia respecto a los poderes del Estado se encuentra ínsita en el mismo centro nuclear de la naturaleza de estas Instituciones. Esta independencia permite a los defensores establecer, en el ejercicio de sus funciones de defensa de los derechos de los ciudadanos, un diálogo con los poderes públicos alejado de intereses políticos, partidarios o de otro tipo que contaminen una perspectiva que considere exclusivamente aquella defensa y la persecución del objetivo de incrementar la eficacia de los derechos y principios constitucionales y estatutarios.

En este sentido, aun cuando sean comisionados de las asambleas legislativas, su desligamiento de todo tipo de mandato imperativo de ninguna autoridad o institución, los hace singularmente aptos para evaluar el contenido de las normas jurídicas y para proponer cambios en las mismas que obedezcan con exclusividad a una perspectiva de protección de los derechos de todos $^{54}$. Obviamente esta perspectiva "que es la que de forma exclusiva y excluyente debe guiar a los defensores al hacer sus propuestas" se debe complementar con otras que deben ser asumidas por las instituciones con capacidad normativa.

\section{- Los defensores de los ciudadanos}

Con esta expresión deseamos insistir en el núcleo esencial de la labor de los defensores, que no es otro que la defensa y promoción de los derechos de los ciudadanos, en especial frente a la actuación de las administraciones públicas. Estas instituciones deben recoger las demandas de los ciu-

54 En este sentido, en PORRAS NADALES, A.J., "La institución del ombudsman en una democracia...", cit, pág. 240, se afirma lo siguiente: "Cabría pensar que la privilegiada posición de diálogo del Defensor del Pueblo con el propio parlamento le debe permitir en este caso un fácil cauce de interlocución para presentar las correspondientes propuestas de reforma legal, en sus periódicos informes. Y de hecho cabe detectar una práctica operativa en tal sentido. La inexistencia en nuestro país (y en general en Europa) de una experiencia similar a la del "legislative oversight" propia de la tradición del sistema de separación de poderes norteamericano, provoca una relativa carencia de mecanismos de retroalimentación que operen como instrumentos correctores de los propios soportes legales. Parece evidente que, en este contexto, uno de los circuitos fundamentales que permitirían asegurar un adecuado feedback del sistema legal a lo largo del tiempo puede recaer sobre las espaldas del Defensor del Pueblon. 
dadanos respecto a posibles vulneraciones y postergaciones de sus derechos y hacer oír su voz ante actuaciones de las administraciones, o ausencia de las mismas, que atenten al estatus jurídico que se debe garantizar a todos los ciudadanos en un Estado social como el nuestro. Como señala Porras Nadales

"si lo expresamos figuradamente en términos schumpeterianos cabría afirmar pues que, de un lado, el Defensor del Pueblo opera en la fase de demanda, es decir, en la esfera del círculo de demandas o necesidades sociales que se expresan a través del sistema de derechos; y por otra, opera en la fase de oferta, entendida como la actuación positiva de las administraciones públicas para responder a las necesidades o demandas ciudadanas. O sea, entre la sociedad y su sistema de necesidades por un lado, y la actividad estatal y su capacidad de respuesta a tales necesidades por el otro" ${ }^{55}$.

Los defensores, por tanto, deben operar como interlocutores válidos entre las necesidades de los ciudadanos y la actividad, normativa y ejecutiva, de las administraciones públicas, trasladando a estas las demandas sociales y jurídicas de aquellos. Esta posición concreta debe ser ocupada por este tipo de instituciones desde el conocimiento del acervo jurídico reconocido a los ciudadanos y con la mirada puesta en el desarrollo y ampliación del mismo exigida por el Texto Constitucional y por los Estatutos de Autonomía en una interpretación histórica que considere de una forma principal la evolución dinámica del Estado social y democrático de Derecho postulado en el primer artículo de la Constitución.

Esta ubicación institucional, de un lado, convierte a los defensores en figuras singularmente idóneas para proponer las modificaciones normativas necesarias para garantizar y ampliar los derechos de los ciudadanos, y, de otro, les obliga a hacerlo adecuadamente con el objetivo de cumplir eficazmente la función que tienen encomendada. Como afirma Carrillo

“... en esta función de indirizzo el Defensor puede llevar a cabo una importante función coadyuvante de las reformas legislativas que son necesarias, haciéndose receptor y transmisor de las quejas ciudadanas ${ }^{56}$.

\section{— Los defensores de algo más que la estricta legalidad}

Se ha puesto de manifiesto con anterioridad que en su alta función de defensa de los derechos de todos las defensorías no utilizan como único y exclusivo parámetro de contraste de la corrección de la actuación administrativa la legalidad, sino que acuden a otros criterios que si bien no son ajenos al or-

55 Ibídem, pág. 236

56 CARRILLO, M., «El Ombudsman como institución de garantía de los derechos de las personas: el papel de los defensores autonómicos" en El Ararteko: un Ombudsman para el Siglo XXI, XXV Cursos de Verano en San Sebastián / XVIII Cursos Europeos - UPV/EHU, 2006, pág. 112. 
denamiento jurídico, entendido este como conjunto orgánico de normas y principios, no responden a la estricta literalidad de las normas. En efecto, principios como el de equidad, justicia material e, incluso, oportunidad ${ }^{57}$, deben estar presentes también en el actuar de los defensores.

Hemos indicado también que esta amplitud de los criterios a emplear por los defensores a la hora de supervisar la actuación de la Administración es plausible cuando de lo que se trata es de proponer modificaciones normativas, puesto que la mayoría de las leyes reguladoras de estas instituciones cuando les atribuyen esta facultad se refieren, con carácter general, a presupuestos para su ejercicio como la constatación de situaciones injustas o perjudiciales. Es decir, en ningún caso se está limitando esta función de impulso del cambio normativo a supuestos donde la aprobación de una norma o su modificación venga impuesta por otra disposición de rango jerárquico superior, sino que, por el contrario, se justifica expresamente en la constatación de situaciones generales, aun cuando sean detectadas a través de casos individuales, que repugnan a principios jurídicos generales que forman parte de nuestra cultura jurídica y que inspiran nuestro sistema constitucional de derechos. No obstante, la configuración sistemática del ordenamiento también contribuye a ampliar el ámbito de decisión de los defensores cuando de proponer cambios normativos se trata, debido a que aquellos pueden observar disfunciones en la propia organización jerárquica de aquel que precisen ser solventadas ${ }^{58}$.

La ausencia de un encorsetamiento ineludible de los defensores a la letra de las normas vigentes cuando se trata de proponer a las administraciones ac-

57 En relación con un posible control de oportunidad de la Administración llevado a cabo por los defensores, en VARELA SUANZES-CARPEGNA, J., "La Naturaleza Jurídica del Defensor del Pueblo", Revista Española de Derecho Constitucional n. ${ }^{\circ} 8$ (mayo-agosto 1983), pág. 70, se señala lo siguiente: "Ahora bien ¿̇cuál es la naturaleza precisa de este control?. Pues bien, siguiendo las más importantes clasificaciones al uso, puede decirse que se trata de un control jurídico o vinculado, en modo alguno necesario, sino tan sólo eventual: de legitimidad pero también de oportunidad,

58 En este sentido, SARASÍBAR MARCO, C., "La Institución del Defensor del Pueblo de Navarra", ENÉRIZ OLAECHEA, F.J. (coord.), Pamplona, Institución del Defensor del Pueblo de la Comunidad Foral de Navarra, 2008, pág. 163. En concreto, respecto al ámbito de actuación de aquella Institución en relación con las modificaciones normativas, allí se expone, con un criterio más restrictivo que el mantenido en el presente trabajo, lo siguiente: «El principal problema que plantea el precepto es la amplitud de la expresión "situaciones injustas o perjudiciales". Ciertamente, una interpretación excesivamente laxa del mismo puede llevar aparejada una alta dosis de subjetivismo en la apreciación de qué sea lo justo o lo injusto y, en definitiva, la sustitución del criterio del legislador o del poder reglamentario por el propio y personal del Defensor del Pueblo. Sin embargo, a mi juicio, el precepto despliega una mayor virtualidad si se parte de la constatación del carácter sistemático del ordenamiento jurídico. Este es, ante todo, organización y sistema, de tal modo que la aplicación rigurosa de una determinada norma puede devenir en lesión o vulneración de derechos si la norma aplicada infringe derechos incorporados al ordenamiento jurídico por fuentes de rango superior. Así sucederá en el caso de Reglamentos que no se acomoden a la regulación de los derechos realizada por las Leyes. O, incluso, en el caso de Leyes que no se avengan con los principios y derechos reconocidos en la Constitución, según el contenido de estos declarado por el Tribunal Constitucional". 
tuaciones dirigidas a garantizar los derechos de todos y la posibilidad de aquellos de utilizar en esta labor otros principios jurídicos, además de la estricta legalidad, para interpretar el alcance de los derechos constitucional y estatutariamente reconocidos, nos hace fijarnos en estas instituciones como elementos de impulso y dinamismo de las normas jurídicas a través de las cuales se estructura nuestro sistema de derechos.

En definitiva, aspectos como los expuestos, no solo convierten a los defensores en instituciones idóneas para proporcionar nuevas perspectivas en relación con el contenido y alcance de las normas jurídicas y con la idoneidad de las mismas para desarrollar y garantizar adecuadamente los derechos de los ciudadanos, sino que, de forma imperativa, exigen que los defensores asuman con intensidad esta dimensión de su actuación. En otras palabras, es necesario asumir que defender adecuadamente los derechos de los ciudadanos, considerados en su totalidad o individualmente, exige, con no poca frecuencia, proponer a los órganos con competencias normativas cambios en el ordenamiento jurídico impuestos por una correcta interpretación y desarrollo de aquellos derechos.

\section{CONSIDERACIONES FINALES}

El papel más conocido de los defensores del pueblo es aquel que consiste en la tramitación y resolución de quejas que los ciudadanos, individualmente considerados o a través de colectivos en los que se integran, les hacen llegar tratando de buscar una solución al problema concreto que se les plantea, proponiendo aquellos, en su caso, a los poderes públicos la adopción de las medidas que procedan para dar cumplida respuesta al ciudadano que busca su protección y la defensa del derecho que considera vulnerado. Esta es la función primaria y más reconocible de los defensores. Ahora bien, las quejas ciudadanas y el resultado de las investigaciones que motiven pueden evidenciar, en ocasiones, deficiencias en la actuación de los poderes públicos de carácter general, que, si bien tienen una consecuencia concreta que es conocida por el defensor de que se trate a través de una queja o mediante una actuación de oficio, extienden sus efectos sobre otros muchos supuestos por poseer un carácter estructural en el sector concreto de la actuación administrativa de que se trate. Los defensores no pueden y no deben circunscribir su actuación de defensa de los derechos de todos a los casos concretos que conocen directamente a través de las quejas que se les presentan, sino que deben extender su mirada también hacia todos aquellos ciudadanos que, pese a no haber acudido directamente a ellos por los motivos que sean, se ven afectados en sus estatus jurídico por una deficiencia genérica que es constatada por el defensor en el desarrollo normal de su actuación. Los defensores del pueblo deben ser capaces, y lo han sido, de viajar desde lo particular a lo general con el objetivo de cumplir eficazmente con la función que tienen encomendada, extrayendo conclusiones generales de presupuestos particulares, sin que ello 
implique, en modo alguno, abandonar el caso singular que les permite emprender aquel viaje ${ }^{59}$.

Esta necesaria evolución desde lo concreto a lo general que los defensores deben estar dispuestos a afrontar cuando una correcta defensa de los derechos de los ciudadanos así lo exija, no tiene por qué detenerse en el nivel ejecutivo de la actuación administrativa y debe traspasar el mismo para adentrarse hasta el nivel normativo. Aquí es donde la extrapolación de lo particular a lo genérico alcanza su mayor virtualidad, y, por ello, cuando la misma se realiza por los defensores su alcance encuentra una nueva dimensión en orden al cumplimiento de su objetivo último de garantizar la eficacia real del derecho de que se trate. Sin duda, es muy relevante la postura adoptada por un defensor respecto a un supuesto de vulneración de un derecho de un ciudadano que este le ha hecho saber a través del conducto establecido, pero también lo es, en otra medida y con otra amplitud, si el defensor, sin abandonar el caso particular planteado, eleva su mirada por encima y es capaz de ver todos aquellos otros supuestos que pueden verse afectados por la misma norma que motiva la vulneración que motivó su actuación inicial.

Esta especial actitud de los defensores respecto al análisis de las quejas que les presentan los ciudadanos y en relación con el contenido de las normas jurídicas que, en ocasiones, se encuentran en el origen de aquellas, cobra una importancia crucial en un Estado social como el constitucionalizado en España, donde sin perjuicio del carácter normativo de la Constitución y de los efectos del mismo sobre los derechos reconocidos en aquella, la efectividad real de muchos de ellos (en especial de los principios rectores de la política social y económica incluidos dentro del Capítulo III, del Título I de la Constitución) requieren de decisiones normativas que especifiquen su contenido y donde se dispongan las medidas organizativas necesarias para su disfrute ${ }^{60}$. A lo anterior se añaden los nuevos Estatutos de Autonomía que han incorporado, a modo de parte dogmática, listas de derechos, especialmente también de contenido económico y social, cuya incorporación estatutaria ha sido admiti-

59 En SÁNCHEZ FÉRRIZ, R., “El Síndic de Greuges. Consideraciones sobre la significación actual de una Institución necesaria para la efectividad de los derechos y libertades", Corts. Anuario de Derecho Parlamentario, núm. 5, 1998, pág.45, se afirma respecto al Síndic de Greuges valenciano, pero en palabras que son trasladables al resto de ombudsman que existen en España que "... las quejas individuales no pierden su razón de ser como objeto inmediato de la atención del Sindico, pero sí pueden ser redimensionadas en pro de una interpretación más operativa y activa de la institución. Las quejas no dejan de ser síntomas puntuales de disfunciones más generales. Por ello, y sin perjuicio de la eficaz intervención del Síndico en casos puntuales, las quejas han de tomarse en cambio como datos o indicios de la necesidad de una actuación más amplia que el Síndico debe exponer y razonar ante el Parlamento pero que este ha de asumir como tarea propia. Porque, a mi juicio, el eventual fracaso, desconocimiento o falta de eco social del Síndico habría de verse como el correspondiente fracaso por parte de la institución parlamentaria que es la que le da soporte institucional y lo nombra para que sea su longa manu en la defensa de derechos".

60 Así, SOlOZÁBAl ECHEVARRÍA, J.J. Nación y Constitución. Soberanía y Autonomía en la forma política española, Biblioteca Nueva, Madrid, 2004, págs. 175 y 176 
da de forma limitada por el Tribunal Constitucional, considerando aquellos derechos de cuño estatutario como mandatos dirigidos a los poderes públicos de la Comunidad Autónoma de que se trate. Por tanto, la reforma de los Estatutos de Autonomía ha introducido nuevas vinculaciones entre desarrollo y eficacia de derechos y el ejercicio de poderes normativos.

A todo lo anterior se añade un protagonismo predominante de las administraciones públicas, cuya actuación es objeto de la supervisión de los defensores, en cuanto encarnaciones del poder ejecutivo en la creación y modificación de las normas jurídicas, sin limitarse este papel preponderante al más obvio desarrollado en el ejercicio de la potestad reglamentaria.

En el panorama descrito, unas instituciones cuya razón de ser es la defensa y protección de los derechos de los ciudadanos, en especial frente a las administraciones públicas, no pueden ser ajenas al ejercicio de estos poderes normativos de la Administración íntimamente vinculados con la virtualidad práctica de los derechos que deben defender. En un momento de desarrollo del Estado social donde la efectividad de los derechos económicos y sociales y la remoción de los obstáculos que impiden su disfrute real y efectivo, en especial para las personas que pertenecen a colectivos en peligro de exclusión, dependen, en gran parte, de medidas de carácter normativo adoptadas por aquellas administraciones, instituciones como los defensores del pueblo deben asumir un papel de impulso de los cambios normativos que sean exigibles y necesarios para lograr que los derechos reconocidos en la Constitución y en los Estatutos de Autonomía tengan una eficacia real para todos.

Hemos reseñado que las leyes reguladoras de los defensores no han sido ajenas a este aspecto concreto, recogiendo todas ellas previsiones concretas en las que se faculta a aquellos para proponer a las instituciones con competencias normativas la aprobación o modificación de normas jurídicas. Igualmente, también se ha expuesto que determinados aspectos relativos a la propia configuración de estas instituciones las hacen especialmente idóneas para realizar una función de impulso de los legisladores, ejerciendo una especie de función prelegislativa o de iniciativa legislativa indirecta ${ }^{61}$. De hecho, no se puede afirmar que esta función no haya sido ejercida por los defensores, ni que este ejercicio no haya tenido un reflejo práctico, y de ello se ha dado cuenta en el presente trabajo.

No obstante, el propio desarrollo del Estado social pone en un primer plano la necesidad de desempeñar correctamente y de forma intensa esta labor del impulso de los cambios normativos dirigidos a garantizar la efectividad de los derechos sociales. En efecto, la defensa de los derechos exige a los defensores, ahora más que nunca, asumir un papel de impulso de las modi-

61 ANGUITA SUSI, A., «El Defensor del Pueblo Andaluz y la protección de los derechos sociales: reflexiones en torno a dos décadas de intervenciones garantistas en el ámbito de los derechos del Capítulo III del Título I de la Constitución", Jornadas sobre reformas estatutarias, derechos sociales y defensores del pueblo autonómicos, Universidad Internacional de Andalucía, Defensor del Pueblo Andaluz, mayo 2005, págs. 160-161. 
ficaciones del ordenamiento jurídico y de dinamización del contenido de las normas que lo integran.

El adecuado ejercicio de esta función opera también como una garantía de implantación real del Estado social, considerando la especial posición institucional de los defensores, como referentes de los ciudadanos en orden a la protección de sus derechos, de un lado, y dotados de un nivel de independencia respecto de los poderes del Estado, de otro. Por tanto, la actuación de los defensores dirigida a proponer la aprobación o modificación de normas no sólo es necesario para el cumplimiento de su función, sino que contribuye a poner en conocimiento de los órganos competentes las reformas que exige la eficacia real de los derechos que integran el estatus constitucional y estatutariamente reconocido a todas las personas.

En definitiva, defender los derechos implica también, de forma casi irrenunciable, impulsar la reforma de las normas que los desarrollan y que establecen las medidas precisas para que ninguna persona se vea excluido de su disfrute real.

TITLE: The role of ombudsmen as promoters of amendments in the legal system-an additional guarantee in the development of social (welfare) state.

AвSTRACT: One of the features of the so called social (welfare) state is the acknowledgment of a series of rights having a distinct social, economic content. Besides, it tries to guarantee a real enjoyment of the said rights. The effectiveness of such rights is often conditioned by the contents of legal rules produced and passed by public administrations. This article examines the functions performed by ombudsmen in order to propose to the aforesaid public administrations the changes in legal rules which are necessary to improve the protection and real effectiveness of the rights recognized by the constitution and by statutes of autonomy. This particular aspect in the activity of ombudsmen, becomes a necessary precondition in their defence of citizen's rights. At the same time it turns into an additional guarantee in the development of the social (welfare) state.

RESUMEN: Una de las características del Estado social es el reconocimiento de derechos de contenido marcadamente social y económico, cuyo disfrute real trata de ser garantizado a todas las personas. La efectividad de tales derechos, en muchos casos, se encuentra condicionada por el contenido de normas juridicas que son elaboradas y aprobadas por las administraciones públicas. En este trabajo se analiza la función que los defensores del pueblo deben llevar a cabo en orden a proponer a aquellas las modificaciones normativas necesarias para mejorar la protección y eficacia real de los derechos reconocidos en la Constitución y en los Estatutos de Autonomía. Esta dimensión concreta de la actuación de los defensores, al tiempo que se convierte en un presupuesto necesario de su intervención en defensa de los derechos de los ciudadanos, constituye una garantía adicional del desarrollo del Estado social.

KeY words: Social (welfare) state. Legal system. Social rights. Effectiveness. Public administration. Ombusdmen. Amendments to legal rules.

Palabras clave: Estado social. Ordenamiento jurídico. Derechos sociales. Eficacia. Administraciones públicas. Defensores del Pueblo. Modificaciones normativas.

FECHA DE RECEPCIÓN: 30.06.2010. FECHA DE ACEPTACIÓN: 28.07.2010. 